\title{
Stabilization versus insurance: welfare effects of procyclical taxation under incomplete markets ${ }^{1}$
}

\author{
James S. Costain \\ Universidad Carlos III de Madrid \\ Michael Reiter \\ Universitat Pompeu Fabra
}

First version: November 2004

This version: August 2005

\author{
Correspondence addresses: \\ Department of Economics \\ Univ. Carlos III \\ Calle Madrid 126 \\ 28014 Getafe (Madrid), Spain \\ jcostain@eco.uc3m.es \\ Department of Economics and Business \\ Universitat Pompeu Fabra \\ Ramon Trias Fargas 25-27 \\ 08005 Barcelona, Spain \\ michael.reiter@upf.edu
}

\footnotetext{
${ }^{1}$ Financial support from the Spanish Ministry of Education (DGES grants PB98-1065, PB98-1066, and MCyT grant SEC2002-01601) is gratefully acknowledged. Thanks to Chris Telmer and Albert Marcet for their helpful comments, and likewise to seminar participants at CEMFI, UPF, Cyprus, Carlos III, Stony Brook, Bern, Granada, SED 2001, SED 2005, SAET 2005, and the Econometric Society 2005. Remaining errors are the responsibility of the authors.
} 


\begin{abstract}
We construct and calibrate a general equilibrium business cycle model with unemployment and precautionary saving. We compute the cost of business cycles and locate the optimum in a set of simple cyclical fiscal policies.

Our economy exhibits productivity shocks, giving firms an incentive to hire more when productivity is high. However, business cycles make workers' income riskier, both by increasing the unconditional probability of unusually long unemployment spells, and by making wages more variable, and therefore they decrease social welfare by around one-fourth or one-third of $1 \%$ of consumption. Optimal fiscal policy offsets the cycle, holding unemployment benefits constant but varying the tax rate procyclically to smooth hiring. By running a deficit of $4 \%$ to $5 \%$ of output in recessions, the government eliminates half the variation in the unemployment rate, most of the variation in workers' aggregate consumption, and most of the welfare cost of business cycles.
\end{abstract}

JEL classification: E24, E32, E62, E63, H21, J64, J65

Keywords: Real business cycles, matching, precautionary saving, unemployment insurance, fiscal policy, incomplete markets, heterogeneity, computation 
In so far as the absence of income-risk pooling reflects "imperfections" in capital markets, and I think it does, the cost of individual income variability measures the potential or actual gain from social insurance, not from stabilization policy.

$$
\text { Robert Lucas (1987), p. } 29 .
$$

The real promise of the Krusell-Smith model and related formulations, I think, will be in the study of the relation of policies that reduce the impact of risk by reducing the variance of shocks (like aggregate stabilization policies) to those that act by reallocating risks (like social insurance policies).

Robert Lucas (2003), p. 10.

\section{Introduction}

Lucas $(1987,2003)$ argued that more aggressive macroeconomic stabilization policy would be unlikely to result in large welfare gains, since aggregate consumption fluctuations are small. ${ }^{1}$ He made clear that his calculation assumed a representative agent, and therefore might not apply to an economy with heterogeneity of individual consumption due to uninsured risk. But then again, individual consumption risk might seem to be a separate issue, possibly calling for social insurance policies, but not central to understanding the benefits from macroeconomic stabilization.

However, in the spirit of Lucas' second quote above, we argue that macroeconomic stabilization and social insurance are interacting policies which ought to be analyzed jointly. If insuring idiosyncratic risk is distortionary, then optimal policy is likely to leave some residual individual risk uninsured, which could increase the benefits of stabilization policy. Likewise, business cycles change the distribution of idiosyncratic risk, so the welfare impact of insurance could also depend on the degree of macroeconomic stabilization.

Therefore, this paper constructs a framework for analyzing stabilization and insurance together. Our model is a real business cycle economy in which

\footnotetext{
${ }^{1}$ By considering a change in variance without changing means, Lucas rules out the possibility that recessions represent a one-sided "gap" below "potential output". This paper likewise focuses on eliminating variance.
} 
productivity shocks cause variations in employment. In the model, labor is indivisible, jobs are formed through a matching technology, and wages are determined by bargaining, so individual labor income is affected both by wage variation and by unemployment risk. We assume that workers are risk averse, and that there are no private markets in which to insure their labor income, so that they have an incentive to smooth their consumption through precautionary saving.

In this setup, aggregate and idiosyncratic risks are intimately related: if firms hire more in response to a productivity shock, workers are more likely to find jobs. It follows that business cycles increase workers' risk in two ways. First, changes in the unemployment rate affect workers' outside options, leading to variation in the wage. Second, even if we hold fixed the unconditional mean of the unemployment rate, variation in hiring will increase the riskiness of labor income by changing the persistence of unemployment spells. The probability of remaining unemployed for many periods depends exponentially on the probability of not finding a job between one period and the next, so variation in transition rates spreads out the unconditional distribution of unemployment spell lengths. Precautionary saving is quite effective in insuring individuals against short unemployment spells. But if the economy sometimes goes into recession, then the unconditional probability of occasionally suffering an exceptionally long unemployment spell, long enough to run out of savings, is substantially increased.

An advantage of using an equilibrium model to derive the relation between aggregate and idiosyncratic risk is that we can easily go beyond the "magical" experiment (as Lucas (2003) called it) of just "switching off" all fluctuation. We assume there is a government which can subsidize the unemployed by taxing the employed, thus distorting employment but helping workers to smooth their consumption. Moreover, by varying these distortions in booms and recessions, the government can stabilize (or amplify) the fluctuations of output and employment. We find that the optimal policy holds unemployment benefits roughly constant over time. However, optimal taxation is strongly procyclical, in order to smooth the cycle. That is, even though labor is more productive in 
booms than in recessions, the government should smooth employment in order to reduce the risks workers face.

\subsection{Relation to previous literature}

Many papers have attempted to extend Lucas' calculation to allow for idiosyncratic risk. Imrohoroglu (1989) compared the welfare levels achieved through precautionary saving in economies with and without an aggregate risk component. She simplified her calculation by holding all prices constant; including general equilibrium effects is much harder, since prices and all other equilibrium quantities can depend on the entire distribution of asset holdings, a very high dimensional object. The numerical methods for calculating distributional dynamics developed by Krusell and Smith (1998) finally permitted Krusell and Smith (1999) to study a model like that of Imrohoroglu with equilibrium prices. Gomes, Greenwood, and Rebelo (2001) used similar methods in a model of search from an exogenous wage distribution. Storesletten, Telmer, and Yaron (2001) used the same methods with a detailed calibration of the individual labor income process based on PSID data. ${ }^{2}$

However, all the papers mentioned above share a common weakness. All include an idiosyncratic risk component - which could be interpreted as the random availability of jobs - but this component is imposed exogenously, instead of being explicitly modeled. Therefore, it is impossible to calculate the value of eliminating aggregate fluctuation without making further assumptions about how this affects the idiosyncratic risk component, which is far from obvious. Different authors have made different assumptions: for example, Atkeson and Phelan (1994) and Krusell and Smith (1999) propose ways of holding idiosyncratic risk fixed when aggregate output is stabilized. Imrohoroglu (1989) and Storesletten et. al. (2001) instead assumed that transition probabilities between different idiosyncratic labor market states vary with the business cycle,

\footnotetext{
${ }^{2}$ An alternative that avoids calculating the dynamics of the asset distribution is to focus on a model in which agents prefer not to save, as Krebs $(2003,2004)$ has done in two papers that highlight the importance of multiple capital stocks and multiple risk factors for the costs of business cycles.
} 
and that by smoothing aggregate fluctuations, these transition probabilities are also stabilized towards their means. This implies a substantial reduction of idiosyncratic risk when business cycles are eliminated, especially in the case of Storesletten et. al. (2001), who found strongly countercyclical labor income variance in the PSID.

Our paper avoids arbitrary assumptions about the relation between aggregate and idiosyncratic risk since we endogenize individual labor income risk through a matching technology. In this context, we find that switching off aggregate shocks stabilizes idiosyncratic transition probabilities, thus lowering the unconditional probability of the longest unemployment spells, and also stabilizes wages. Our calibration, following Costain and Reiter (2005), is chosen to ensure that both cyclical unemployment fluctuations and policy-induced changes in unemployment are consistent with the data. With this calibration, we find that the government can eliminate most of the welfare loss from cycles by using countercyclical taxation to stabilize hiring. In other words, we show that business cycles increase idiosyncratic risk, as in Imrohoroglu (1989) and Storesletten et. al. (2001) - and therefore they are several times more costly than Lucas found. However, the increase in idiosyncratic risk caused by aggregate fluctuation is less than that in Storesletten et. al. (2001) and Beaudry and Pages (2001), so we find smaller costs of business cycles than they do.

Since we compute optimal policy, our results can also be contrasted with those of the literature on optimal taxation in business cycle models. The environments closest to ours are those where the government can insure itself through some state-contingent instrument (Lucas and Stokey 1983; Chari, Christiano, and Kehoe 1994; Scmitt-Grohe and Uribe 2004); these papers, unlike ours, find that labor taxes should be roughly constant. In papers where the government lacks instruments like state-contingent capital taxes, approximate labor tax smoothing is still the usual result, but shocks induce a random walk in labor tax rates (Barro 1979; Aiyagari, Marcet, Sargent, and Seppala 2000). However, Greenwood and Huffman (1991) find that nonzero taxation amplifies real business cycles, and therefore, like us, they find welfare gains from smoothing the cycle with procyclical tax rates. 
The next section describes our economy. Section 3 discusses the set of fiscal policies we allow. Section 4 describes the algorithm we use to calculate our equilibrium distributional dynamics. Section 5 discusses how we evaluate social welfare, and Section 6 defines parameters. Section 7 analyzes the results: our steady state equilibrium, an equilibrium with business cycles, and the effects of various fiscal policies. Section 8 concludes.

\section{The economic environment}

\section{$2.1 \quad$ State space}

Time is discrete. Fluctuations are driven by an aggregate technology process $Z_{t}$ that follows a two-state Markov process. The two technology states are $Z^{1}$, which we call "recession", and $Z^{2}$, which represents a "boom". The probability of transition from the bad state $Z^{1}$ to the good state $Z^{2}$ is $\pi_{12}$, and $\pi_{21}$ is the probability of the opposite transition. Thus, if $\mathbf{1}(x)$ is an indicator function taking the value 1 when statement $x$ is true, and 0 otherwise, the Markov process can be summarized as follows:

$$
\left(\begin{array}{l}
\operatorname{prob}\left(Z_{t+1}=Z^{1} \mid Z_{t}\right) \\
\operatorname{prob}\left(Z_{t+1}=Z^{2} \mid Z_{t}\right)
\end{array}\right)=\left(\begin{array}{cc}
1-\pi_{12} & \pi_{21} \\
\pi_{12} & 1-\pi_{21}
\end{array}\right)\left(\begin{array}{c}
\mathbf{1}\left(Z_{t}=Z^{1}\right) \\
\mathbf{1}\left(Z_{t}=Z^{2}\right)
\end{array}\right)
$$

There are three types of agents in the economy. There is a continuum of risk-averse workers of measure 1 . There is also a continuum of risk-neutral capitalists, whose measure need not be specified. The third agent is the government.

Workers can be in one of three labor market states $s \in\{0,1,2\}$. State 0 represents unemployment, while states 1 and 2 are employment in bad and good jobs, respectively. The mass of workers employed in bad jobs at time $t$ is $N_{t}^{b}$, and the mass employed in good jobs is $N_{t}^{g}$; total employment is $N_{t} \equiv N_{t}^{b}+N_{t}^{g} \equiv 1-U_{t}$.

The other relevant state variable for a worker is her asset holdings $a$. To rule out Ponzi schemes, we assume that assets must satisfy a liquidity constraint $a \geq-\bar{a}$. We will write the time- $t$ joint cumulative distribution function over 
labor market status and asset holdings as $\Phi_{t}(s, a):\{0,1,2\} \times[-\bar{a}, \infty) \rightarrow[0,1]$. Note that we can back out the fraction of agents in each labor market state from $\Phi$; for example, the number of unemployed is

$$
U_{t}=\int_{-\bar{a}}^{\infty} \Phi_{t}(0, d a)
$$

The pair $\Omega_{t} \equiv\left(Z_{t}, \Phi_{t}\right)$ is the minimum aggregate state variable for this model, and the minimum idiosyncratic state variable is $\left(s_{t}, a_{t}\right)$. We conjecture that there exists an equilibrium in which the aggregate variables determined at $t$ depend only on $\Omega_{t}$, while individual decisions at $t$ depend only on $\left(s_{t}, a_{t}, \Omega_{t}\right)$. In such an equilibrium, the time $t+1$ distribution of idiosyncratic states will depend on the previous distribution, and on the technology shocks at $t$ and $t+1 .^{3}$ We call this relation $T$ :

$$
\Phi_{t+1}=T\left(\Phi_{t}, Z_{t}, Z_{t+1}\right)
$$

To determine $T$, we must now discuss individual behavior.

\subsection{The worker's problem}

Workers search for jobs, work, and choose between consumption and saving. Their instantaneous utility function is $u(c, l)$, where $c$ is consumption and $l$ is leisure; the discount factor from one period to the next is $\beta$. However, for the purposes of this paper we will fix search effort and work effort, while making the consumption/saving decision endogenous. Thus, moral hazard effects are beyond the scope of the paper.

We will assume that time spent working or searching is $h(s)=1-l(s)$; in other words, it depends only on the individual labor market state. We will also make assumptions below to ensure that labor income is $w(s, \Omega)$, depending only on the labor market state and on the aggregate state. In particular, this means that wages do not depend on asset holdings. Labor income $w(s, \Omega)$ is

\footnotetext{
${ }^{3}$ The distribution $\Phi_{t+1}$ depends on the shock $Z_{t+1}$ because $Z_{t+1}$ affects the probabilities that the new jobs formed at $t+1$ are bad or good.
} 
defined after taxes and transfers, so this notation is used for state $s=0$ to represent unemployment benefits (which we will assume are the only form of income received by the unemployed). Savings yield a fixed interest rate $R-1$.

We will consider several types of labor market transitions. Job separation from bad jobs and good jobs occurs with probabilities $\delta^{b}$ and $\delta^{g}$, respectively, where $\delta^{b} \geq \delta^{g}$. Unemployed workers who search when the current technology shock is $Z$ find bad jobs with probability $p^{b}\left(Z^{\prime}, Z, \Phi\right)$, or good jobs with probability $p^{g}\left(Z^{\prime}, Z, \Phi\right)$. We assume that good jobs are more plentiful in good times: that is, $p^{g}\left(Z^{1}, Z, \Phi\right) \leq p^{g}\left(Z^{2}, Z, \Phi\right)$. Furthermore, workers in bad jobs may be promoted to good jobs, which occurs with probability $p^{\text {prom }}$, which we treat for simplicity as an exogenous constant. The focus of our analysis is on the hiring rates $p^{b}$ and $p^{g}$, which depend endogenously on labor market tightness and thus on the hiring choices of capitalists.

Suppose the aggregate state at $t$ is $(Z, \Phi)$, and the technology shock at $t+1$ is $Z^{\prime}$. Then we can write the transition from the unemployment and employment rates $\left(U, N^{b}, N^{g}\right)$ at time $t$ to the next period's rates $\left(U^{\prime}, N^{b \prime}, N^{g \prime}\right)$ conditional on $Z, \Phi$, and $Z^{\prime}$, as follows:

$$
\left(\begin{array}{c}
U^{\prime} \\
N^{b \prime} \\
N^{g^{\prime}}
\end{array}\right)=\left(\begin{array}{ccc}
1-p^{b}\left(Z^{\prime}, Z, \Phi\right)-p^{g}\left(Z^{\prime}, Z, \Phi\right) & \delta^{b} & \delta^{g} \\
p^{b}\left(Z^{\prime}, Z, \Phi\right) & 1-\delta^{b}-p^{\text {prom }} & 0 \\
p^{g}\left(Z^{\prime}, Z, \Phi\right) & p^{\text {prom }} & 1-\delta^{g}
\end{array}\right)\left(\begin{array}{c}
U \\
N^{b} \\
N^{g}
\end{array}\right)
$$

Equivalently, we could state this equation as a relation between an individual's probabilities of being in the various labor market states $s$ at $t$, and the probabilities of being in those states at $t+1$.

We now have enough information to define the worker's problem in recursive form, in terms of the value function $W(s, a ; Z, \Phi)$.

Worker's Bellman equation:

$$
\begin{aligned}
W(s, a ; Z, \Phi)= & \max _{c} u(c, 1-h(s))+\beta E\left\{W\left(s^{\prime}, a^{\prime} ; Z^{\prime}, \Phi^{\prime}\right) \mid s, Z, \Phi\right\} \\
\text { s.t. } & (1),(3),(4), \quad a^{\prime}=R a+w(s, Z, \Phi)-c, \quad \text { and } \quad a^{\prime} \geq-\bar{a}
\end{aligned}
$$

In this equation, the expectation operator is understood to refer to the exogenous Markov process (1) for the aggregate shock $Z$, and also to the transition 
laws (3) and (4) for the distribution $\Phi$ and the idiosyncratic labor state $s$ conditional on the realization of $Z^{\prime}{ }^{4}$

\subsection{The capitalists' hiring problem}

Capitalists are risk neutral; their discount factor $1 / R$ determines the interest rate $R-1$ mentioned above.

Capitalists may open job vacancies; these vacancies, together with the total job search of workers, determine the rate of job matching. As is common in matching models, we make constant returns to scale assumptions in production and in matching, which permits us, without loss of generality, to consider the opening of vacancies one by one. Job vacancies may be in one of three states $z \in\{0,1,2\}$, where $z=0$ means that the vacancy is empty, $z=1$ means that the vacancy has been filled with a bad job, and $z=2$ means that the vacancy has been filled with a good job. We assume no adjustment costs in vacancy creation; therefore vacancies are opened or closed until the value of an empty vacancy is zero.

Let the cost of holding open a vacancy be $\kappa$ per period. Suppose that paying this cost results in probability $q^{b}\left(Z^{\prime}, Z, \Phi\right)$ of forming a bad job, and probability $q^{g}\left(Z^{\prime}, Z, \Phi\right)$ of forming a good job, per period. Then if we know the value of a filled job $J(z, Z, \Phi)$ for $z \in\{1,2\}$, the zero profit condition on unfilled vacancies $(z=0)$ must be

$J(0, Z, \Phi)=0=-\kappa+\frac{1}{R} E\left\{q^{b}\left(Z^{\prime}, Z, \Phi\right) J\left(1, Z^{\prime}, \Phi^{\prime}\right) \mid \Omega\right\}+\frac{1}{R} E\left\{q^{g}\left(Z^{\prime}, Z, \Phi\right) J\left(2, Z^{\prime}, \Phi^{\prime}\right) \mid \Omega\right\}$

where the expectation is taken with respect to the dynamics (1) and (3) of the aggregate state variables $Z$ and $\Phi$.

The value $J$ of a filled job will depend on the quality of the match, $z \in$ $\{1,2\}$, and on the aggregate state $\Omega$. In general, it would also depend on

\footnotetext{
${ }^{4}$ This Bellman equation is based on the assumption that workers never quit. This can be ensured by making workers sufficiently impatient compared with the interest rate, so that those who start with low assets will never accumulate enough to prefer quitting into unemployment. We check this after solving our Bellman equations.
} 
the asset holdings of the worker in the match. However, we will see that in our framework, the wage does not depend on asset holdings; and we will choose parameters such that workers never accumulate sufficient assets to make quitting into unemployment desirable. These two aspects of our specification suffice to make the value of a filled job independent of the worker's assets.

The marginal product of a filled job is $y(z, Z)$, net of capital costs. The firm must pay the worker the equilibrium wage associated with the quality of the job, $w(z, Z, \Phi)$, and it must also pay a tax $\tau(Z, \Phi)$ to the government. As we saw earlier in the case of the worker, bad and good jobs separate at rates $\delta^{b}(Z)$ and $\delta^{g}(Z)$, respectively, and bad jobs are promoted to good jobs with constant probability $p^{\text {prom }}$. Thus filled jobs $(z \in\{1,2\})$ expect the following transitions:

$$
\left(\begin{array}{l}
\operatorname{prob}\left(z^{\prime}=0 \mid z\right) \\
\operatorname{prob}\left(z^{\prime}=1 \mid z\right) \\
\operatorname{prob}\left(z^{\prime}=2 \mid z\right)
\end{array}\right)=\left(\begin{array}{cc}
\delta^{b} & \delta^{g} \\
1-\delta^{b}-p^{\text {prom }} & 0 \\
p^{\text {prom }} & 1-\delta^{g}
\end{array}\right)\left(\begin{array}{c}
\mathbf{1}(z=1) \\
\mathbf{1}(z=2)
\end{array}\right)
$$

This information now allows us to recursively define the value $J(z ; Z, \Phi)$ of a filled job $(z \in\{1,2\})$.

Bellman equation for a filled job:

$$
J(z ; Z, \Phi)=y(z ; Z)-\tau(Z, \Phi)-w(z, Z, \Phi)+\frac{1}{R} E\left\{J\left(z^{\prime} ; Z^{\prime}, \Phi^{\prime}\right) \mid z, Z, \Phi\right\}
$$

$$
\text { s.t. } \quad(1),(3) \text {, and }(7)
$$

\subsection{The labor market}

We assume that total matches at $t+1$ are given by

$$
M_{t+1}=\mu V_{t}^{1-\lambda} U_{t}^{\lambda}
$$

where $V_{t}$ is total vacancies. Now suppose that in equilibrium, total vacancies are $V(Z, \Phi)$. We also define labor market tightness as $\theta(Z, \Phi)=V(Z, \Phi) / U$. Let $\pi^{g}(Z)$ be the fraction of new jobs which turn out to be good. Then $p^{g}\left(Z^{\prime}, Z, \Phi\right)=\pi^{g}\left(Z^{\prime}\right) \mu \theta(Z, \Phi)^{1-\lambda}$ and $p^{b}\left(Z^{\prime}, Z, \Phi\right)=\left(1-\pi^{g}\left(Z^{\prime}\right)\right) \mu \theta(Z, \Phi)^{1-\lambda}$. 
Given these job-finding rates for the workers, the probability of filling jobs with bad and good matches must be

$$
q^{b}\left(Z^{\prime}, Z, \Phi\right)=\frac{p^{b}\left(Z^{\prime}, Z, \Phi\right) U_{t}}{V(Z, \Phi)}
$$

and

$$
q^{g}\left(Z^{\prime}, Z, \Phi\right)=\frac{p^{g}\left(Z^{\prime}, Z, \Phi\right) U_{t}}{V(Z, \Phi)}
$$

Note that the rates $q^{b}$ and $q^{g}$ can be written as functions of $Z^{\prime}, Z$, and $\Phi$ only, since $U$ can be calculated a function of $\Phi$, using (2).

\subsection{Wage determination}

Following much of the matching literature, we assume that the wage is determined by Nash bargaining, at the beginning of each period, over the surplus arising from the match. Bargaining occurs not only at new matches, but also at continuing matches, on a period-by-period basis.

We assume that bargaining occurs at the "sectoral" level. A sector is some subset of firms that all have the same type $z$; it is large compared to individual workers and firms but is small compared to the economy as a whole. In each sector, all workers bargain together as a union. Firms also band together for bargaining. We simplify the bargaining situation by assuming that the definition of a sector is independent between one period and the next, which implies that the union's problem is entirely static. ${ }^{5}$

Workers' unions maximize the sum of all members' utilities. In order to define the wage bargaining problem, we will have to calculate the worker's value function for any possible wage, instead of defining it only for the equilibrium wage, as we did earlier in the worker's Bellman equation. If an employed

\footnotetext{
${ }^{5}$ The "sectoral" bargaining assumption is made purely for technical convenience. By making unions regroup in new sectors each period, we eliminate any union-specific effects of one period's bargaining outcome on the next period's game. By averaging over individuals, we eliminate any dependence of the wage on a given worker's asset holdings. In theory, individual assets could affect both this period's and future wages, but dealing with these complications is beyond the scope of this paper.
} 
worker receives the wage $w$ during a given period (and expects the equilibrium wage thereafter), then her surplus, relative to the value of unemployment, is

$$
\begin{array}{r}
\Sigma^{W}(w, s, a ; \Omega)=\max _{c} u(c, 1-h(s))+\beta E\left\{W\left(s^{\prime}, a^{\prime} ; \Omega^{\prime}\right) \mid s, \Omega\right\}-W(0, a, \Omega) \\
\text { s.t. }(1),(3),(4), \quad a^{\prime}=R a+w-c, \quad \text { and } a^{\prime} \geq-\bar{a}
\end{array}
$$

We assume that unions value the utilities of their members equally, so that they attempt to maximize the average surplus of their members. Thus a union's surplus is

$$
\Sigma^{U}(w, s ; \Omega)=\int \Sigma^{W}(w, s, a ; \Omega) \Phi(s, d a)
$$

We define the firm's surplus likewise, for any given wage $w$ during one period, taking as given the equilibrium wage in future periods. Given that the option of separation has value zero,

$$
\begin{gathered}
\Sigma^{F}(w, z ; \Omega)=y(z ; Z)-\tau(\Omega)-w+\frac{1}{R} E\left\{J\left(z^{\prime} ; \Omega^{\prime}\right) \mid z, \Omega\right\} \\
\text { s.t. }(1),(3) \text {, and }(7)
\end{gathered}
$$

In principle, firms' unions also average over their members' surpluses; but since $a$ does not enter the firms' surplus function, averaging leaves the surplus unchanged.

The workers' bargaining weight is denoted $\sigma \in(0,1)$. Thus the Nash bargaining problem (for $z \in\{1,2\}$ ) is

$$
w(z, \Omega)=\underset{w}{\operatorname{argmax}}\left[\Sigma^{U}(w, z ; \Omega)\right]^{\sigma}\left[\Sigma^{F}(w, z ; \Omega)\right]^{1-\sigma}
$$

\section{Fiscal policy}

As we emphasized already, by endogenizing employment and idiosyncratic risk we can do more than just measure the cost of business cycles: we can also calculate the optimal cyclical fiscal policy. Like other optimal policy papers 
(e.g. Chari et. al. 1994) we ignore political economy issues, and many realworld complications like uncertainty and implementation lags. Even with these simplifications, finding the optimal policy is difficult, because the space of possible fiscal policies is huge. For example, taxes $\tau$ could be progressive or time-varying, or in general could even vary with the infinite-dimensional aggregate state $(Z, \Phi)$. Since it is already challenging to compute our infinitedimensional equilibrium conditional on a given fiscal policy, it is essential to simplify the policy space before searching for an optimum. We will see that several key aspects of stabilization and insurance policy can be captured with just three parameters: the mean level of unemployment benefits, and two parameters that index the variability of benefits and the deficit.

The question of optimal public spending is outside the scope of this paper: we simply calibrate a realistic constant spending level $G .{ }^{6}$ A constant $G$ with fluctuating productivity could make taxes countercyclical and destabilizing, so it will therefore be interesting to allow the government to run a countercyclical deficit. For simplicity, we require that the deficit be a function of the aggregate productivity shock $Z$ only. Such a deficit can be supported by a market if we assume that time-independent insurance contracts conditional on future productivity shocks $Z_{t}$ are sold at some initial date $t=0$, when both the government and the capitalists are "behind the veil of ignorance", with no information about the initial realization of $Z$. At this time, the capitalists are willing to sell any amount $\hat{X}$ of unconditionally fair insurance paying $X\left(Z^{1}\right) \equiv\left(2 \pi_{12} /\left(\pi_{12}+\pi_{21}\right)\right) \hat{X}$ to the government in bad times, and $X\left(Z^{2}\right) \equiv-\left(2 \pi_{21} /\left(\pi_{12}+\pi_{21}\right)\right) \hat{X}$ in good times. We will study how much insurance $\hat{X}$ the government should demand.

Like the deficit, we restrict the unemployment insurance payment to be a function of $Z$ only, with mean $\bar{b}$ and variability indexed by $\hat{b}$ :

$$
w(0, \Omega) \equiv b(Z) \equiv \bar{b}+\frac{2 \pi_{12}}{\pi_{12}+\pi_{21}} \hat{b} \mathbf{1}_{Z=Z^{1}}-\frac{2 \pi_{21}}{\pi_{12}+\pi_{21}} \hat{b} \mathbf{1}_{Z=Z^{2}}
$$

\footnotetext{
${ }^{6}$ Note that "demand-side" stabilization by varying public spending is uninteresting in our model. With risk-neutral capitalists, goods demand is perfectly elastic, so government spending perfectly crowds out private spending, leaving output and employment unchanged. Therefore, we focus on "supply-side" stabilization, through variations in tax rates.
} 
Finally, we assume that taxes adjust to balance the budget in each period (after insurance transfers $\hat{X})$, which lets us simplify the tax rate to $\tau(\Omega) \equiv \tilde{\tau}(Z, U)$. That is, taxes depend on the technology shock and on unemployment, but not on the asset distribution $\Phi$, as we see from the government budget constraint:

$$
G+b\left(Z_{t}\right) U_{t}=X\left(Z_{t}\right)+\tilde{\tau}\left(Z_{t}, U_{t}\right)\left(1-U_{t}\right)
$$

More importantly, with these fiscal instruments we can ignore government bonds, an additional state variable that would substantially complicate our numerical work. The fair insurance transfers $X(Z)$ permit the government to tax less than it spends in some periods, just like bond sales would, but they are a numerically simpler (and theoretically superior) way to achieve this.

Thus three parameters summarize our fiscal policy space: the mean $\bar{b}$ and countercyclicality $\hat{b}$ of the UI benefit, plus the countercyclicality $\hat{X}$ of the government deficit. The stabilizing properties of fiscal policy are illustrated in Figure 1, which shows the policy space conditional on a given average benefit $\bar{b}$. Note that the tax on labor $\tilde{\tau}(Z, U)$ and the unemployment subsidy $b(Z)$ both act as wedges between the cost and benefit of working, and their sum is a measure of the total distortion of employment. Thus we can see whether policy stabilizes or destabilizes employment by checking whether the total distortion $\tilde{\tau}(Z, U)+b(Z)$ is procyclical or countercyclical.

At the origin in the graph, the government always runs a balanced budget, and pays a constant UI benefit, so taxes must rise in recessions. Thus the overall fiscal stance is destabilizing: $\tau+b$ is lower in booms than in recessions. We thus might expect to achieve higher welfare with a countercyclical deficit, by moving along the horizontal axis to the point where both benefits and taxes are smoothed over the cycle. More precisely, exact tax smoothing is unachievable in our policy space, since by defining taxes as a residual we make $\tau$ depend on $U$ as well as $Z$. Therefore, the point defined as "tax smoothing" in Fig. 1 is that which achieves the same average tax rate in booms and recessions:

$$
E\left(\tau \mid Z^{1}\right)=E\left(\tau \mid Z^{2}\right)
$$

when benefits are also smoothed $(\hat{b}=0)$. 
Hence, rightward movements in Figure 1 represent greater countercyclicality of the deficit and greater procyclicality of taxes and distortions. Moving straight upwards in the graph increases the countercyclicality of benefits, making taxes and distortions more countercyclical too. It is also interesting to consider movements in the $+45^{\circ}$ direction, which can be thought of as lump sum aggregate insurance transfers. That is, if UI payments are increased by $\epsilon$ in recessions, and taxes are decreased by $\epsilon$ in recessions, then distortions are unchanged, leaving employment roughly unchanged, and therefore the government deficit should rise by approximately $\epsilon$ per capita. Thus the "constant distortions" curve in the graph, defined as

$$
E\left(\tau \mid Z^{1}\right)+b\left(Z^{1}\right)=E\left(\tau \mid Z^{2}\right)+b\left(Z^{2}\right)
$$

has a slope of approximately one. Points to the right of the curve have procyclical distortions, so fiscal policy stabilizes employment and output; points to the left have countercyclical distortions and are destabilizing. Movements up along the curve represent nondistortionary countercyclical payments from the government to all workers, independent of employment status.

This fiscal policy space lets us evaluate the gains from running a deficit to smooth taxes and distortions. It also allows us to go further, making distortions procyclical, counteracting the fluctuations in employment and output. Alternatively, the government might run a countercyclical deficit for a different reason: to help insure households against the aggregate technology shock (an insurance market which, by assumption, is closed to workers in our economy). By seeing whether welfare improves in the horizontal direction, or in the $+45^{\circ}$ direction, we can see whether tax smoothing, or employment smoothing, or filling in the missing aggregate insurance market best summarizes optimal policy. We will explore these issues by computing equilibrium over a grid of possible cyclical policies $\hat{X}$ and $\hat{b}$, and we will also consider changing the average unemployment benefit $\bar{b}$. 


\section{Computing equilibrium}

For any given fiscal policy $(\hat{X}, \hat{b}, \bar{b})$, we can solve this model with the general equilibrium backwards induction algorithm of Reiter (2002). The algorithm is based on the observation that if we know the period $t+1$ value functions, then we have sufficient information to compute the period $t$ equilibrium at any given aggregate state $\Omega_{t}=\left(Z_{t}, \Phi_{t}\right)$. Thus, in principle, we can work backwards to find the general equilibrium (just as the standard backwards induction algorithm works backwards to find the solution of a single optimization problem). In practice we must solve for equilibrium over a grid of possible values of $\Omega_{t}$, and then interpolate whenever we need to evaluate the value function elsewhere. Moreover, since $\Phi_{t}$ is infinite-dimensional, we must find an adequate way to describe it with a finite list of statistics. This issue is familiar from other recent approaches to computing heterogeneous agent models, like those of Krusell and Smith (1998) and den Haan (1997).

The algorithm consists of the following steps.

1. Choose a vector $m$ of moments (or other statistics) which approximately represent the distribution $\Phi$.

2. Construct a grid $\mathcal{M}$ over possible values of these moments, where equilibrium will be evaluated: $\mathcal{M} \equiv\left\{m_{1}, m_{2}, \ldots, m_{g}\right\}$.

3. Choose a mapping $\hat{\Phi}(m)$ that uniquely defines a distribution $\Phi$ for any given value of the moments $m$.

4. Initialize the value functions $W$ and $J$ to $W_{0} \equiv 0$ and $J_{0} \equiv 0$ for some final period $T$.

5. Assume that the time $t$ equilibrium implies value functions $W_{j}$ and $J_{j}$. For each aggregate state $(Z, m)$ in the grid $\left\{Z^{1}, Z^{2}\right\} \times \mathcal{M}$, solve for the time $t-1$ equilibrium, assuming that the time $t-1$ distribution is $\hat{\Phi}(m)$. Call the resulting time $t-1$ value functions $W_{j+1}$ and $J_{j+1}$.

6. Repeat step 5 until $W$ and $J$ converge.

As the calculation progresses, one can alter the chosen set of moments $m$ or the moments-to-distributions mapping $\hat{\Phi}$ for consistency with the simulated dynamics. 
The backwards induction step (5.), in which we calculate equilibrium at each point in the aggregate grid, requires more detailed discussion. Thus, suppose we have performed $j$ time iteration steps, so that we know the $j$ th iterates of the value functions, $W_{j}$ and $J_{j}$ (the time $t$ values). Then we can perform the following fixed-point calculation to find the $j+1$ st iterate of the equilibrium, including $W_{j+1}$ and $J_{j+1}$ (the time $t-1$ values).

$5 \mathrm{~A}$. Choose a point $(Z, m)$ in the aggregate grid $\left\{Z^{1}, Z^{2}\right\} \times \mathcal{M}$. Assume that the current (time $t-1$ ) aggregate state is $\Omega=(Z, \hat{\Phi}(m))$. Calculate the associated tax rate $\tilde{\tau}(Z, U)$, using equation (17).

5 B. Guess the next period's conditional distributions $\Phi^{\prime}=T\left(Z, \Phi, Z^{\prime}\right)$. In other words, guess each element of the moment vector $m^{\prime}=T^{m}\left(Z, m, Z^{\prime}\right)$ which would result from the time $t-1$ state $\Omega$, conditional on transition to each possible $Z^{\prime} \in\left\{Z^{1}, Z^{2}\right\}$ at $t$.

5 C. Using the surplus equations (12), (13), (14), and the worker's Bellman equation (5), calculate the surplus functions $\Sigma^{W}(w, z, a, \Omega), \Sigma^{U}(w, z, \Omega)$, $\Sigma^{F}(w, z, \Omega)$, and the unemployment value function $W(0, a, \Omega)$ for the current point $\Omega$.

5D. Given the surplus functions $\Sigma^{U}$ and $\Sigma^{F}$, solve the Nash bargaining problem to calculate the wage $w(z ; \Omega)$.

5 E. Plug the wage into the Bellman equations (5) and (8) to update the value functions $W$ and $J$; also calculate the consumption policy $c(s, a, \Omega)$.

$5 \mathrm{~F}$. Using the consumption policy function $c$ and the wage function $w$ to calculate the implied beginning-of-next-period asset holdings $a^{\prime}$, update the moment vector $m^{\prime}=T^{m}\left(Z, m, Z^{\prime}\right)$ associated with each $Z^{\prime} \in\left\{Z^{1}, Z^{2}\right\}$.

$5 \mathrm{G}$. Iterate on steps $5 \mathrm{C}-5 \mathrm{~F}$ until the time $t-1$ equilibrium converges. (In other words, find a fixed point of the mapping from the guessed time $t$ vectors $m^{\prime}$ to the true time $t$ vectors $m^{\prime}$.)

$5 \mathrm{H}$. Repeat steps $5 \mathrm{~A}-5 \mathrm{G}$ for all grid points in $\left\{Z^{1}, Z^{2}\right\} \times \mathcal{M}$.

Note that steps (5C.) and (5E.) involve evaluating the time $t$ value functions $W_{j}$ and $J_{j}$ at the guessed time $t$ moment vectors $m^{\prime}$. These future moments will not normally lie in the aggregate grid $\left\{Z^{1}, Z^{2}\right\} \times \mathcal{M}$, so interpolation is required. For further details on the algorithm, see Reiter (2002). 


\section{Welfare criterion}

Since we are working with a dynamic, stochastic, heterogeneous agent model, we must specify carefully how we weight payoffs over time, states, and agents. First, we sum the utility of all workers with equal weights. As for the capitalists, since they are risk neutral and competitive, they are indifferent to all new job formation in this model. However, they also own the initial stock of existing jobs, and the value of this asset will vary with changes in policy. Therefore we add the value of these existing jobs into our social welfare function, converting them into utility units by multiplying by workers' average marginal utility of consumption. We will see, though, that the value of existing jobs plays only a small role in our welfare calculations.

As a benchmark, we compute social welfare in the equilibrium of a static economy in which the aggregate shocks are shut off. That is, the probability that any new job is good, and the aggregate component of labor productivity, are both set to their unconditional means. The deficit is set to zero $(\hat{X}=0)$, and UI is set to a constant level $\bar{b}_{0}$. Since there is no aggregate uncertainty, this model converges over time to a steady state distribution of assets and employment which we call $\bar{\Phi}$, with a level of social welfare $\overline{\mathcal{V}}$.

We first compare this to an analogous economy with the aggregate shocks switched on, which we call the dynamic benchmark. We continue to assume a balanced budget $(\hat{X}=0)$ and the same constant unemployment benefit $\bar{b}_{0}$. The state of this economy fluctuates over time, so for comparability we evaluate its welfare at the static benchmark distribution $\bar{\Phi}$, and we average over the two possible initial shocks $Z_{0}$. That is, using the notation $V(Z, \Phi \mid \hat{X}, \hat{b}, \bar{b})$ to represent the social welfare (including the value of existing jobs) of the dynamic economy in any given aggregate state $(Z, \Phi)$, given any fiscal policy $(\hat{X}, \hat{b}, \bar{b})$, our dynamic benchmark welfare measure is

$$
\mathcal{V}^{*} \equiv \frac{\pi_{1}}{\pi_{1}+\pi_{2}} V\left(Z^{1}, \bar{\Phi} \mid 0,0, \bar{b}_{0}\right)+\frac{\pi_{2}}{\pi_{1}+\pi_{2}} V\left(Z^{2}, \bar{\Phi} \mid 0,0, \bar{b}_{0}\right)
$$

Note that since it evaluates social welfare at $\bar{\Phi}$, the dynamic benchmark welfare measure $\mathcal{V}^{*}$ implicitly includes the value of the transition path from the fixed 
initial distribution $\bar{\Phi}$ to the new fluctuating distribution of distributions that results from the shocks.

To clarify units, we express the cost of business cycles as a loss of consumption, as in Lucas $(1987,2003)$. That is, we calculate the permanent proportional change $\Delta^{*}$ in workers' consumption distribution which would yield the same social welfare loss as that caused by business cycles:

$$
\mathcal{V}^{*}-\overline{\mathcal{V}}=E_{\bar{\Phi}}\left[\frac{u\left(c\left(1+\Delta^{*}\right), 1-h\right)}{1-\beta}\right]-E_{\bar{\Phi}}\left[\frac{u(c, 1-h)}{1-\beta}\right]
$$

The expectation operator $E_{\bar{\Phi}}$ in this equation refers to cross-sectional averages in the static benchmark economy.

The welfare associated with any other policy $(\hat{X}, \hat{b}, \bar{b})$ in the dynamic economy is likewise evaluated at the static benchmark distribution, averaging over possible initial shocks:

$$
\mathcal{V}(\hat{X}, \hat{b}, \bar{b}) \equiv \frac{\pi_{1}}{\pi_{1}+\pi_{2}} V\left(Z^{1}, \bar{\Phi} \mid \hat{X}, \hat{b}, \bar{b}\right)+\frac{\pi_{2}}{\pi_{1}+\pi_{2}} V\left(Z^{2}, \bar{\Phi} \mid \hat{X}, \hat{b}, \bar{b}\right)
$$

The static benchmark economy again serves as a reference point for computing consumption certainty equivalents. The consumption cost of cycles under policy $(\hat{X}, \hat{b}, \bar{b})$ is written $\Delta(\hat{X}, \hat{b}, \bar{b})$, and is defined as follows:

$$
\mathcal{V}(\hat{X}, \hat{b}, \bar{b})-\overline{\mathcal{V}}=E_{\bar{\Phi}}\left[\frac{u(c(1+\Delta(\hat{X}, \hat{b}, \bar{b})), 1-h)}{1-\beta}\right]-E_{\bar{\Phi}}\left[\frac{u(c, 1-h)}{1-\beta}\right]
$$

Since $\Delta^{*}$ and $\Delta(\hat{X}, \hat{b}, \bar{b})$ both include the cost of "switching on" cycles, the welfare impact of the policy change itself is given by their difference.

\section{Parameterization}

\section{Unemployment volatility}

Before discussing the parameters in Table 1, we begin by explaining a crucial calibration issue which initially caused us some difficulty. Changes in the probability of unemployment are central to our arguments. Therefore, in order to evaluate the welfare effects of stabilization and insurance policies, our model 
must generate quantitatively realistic cyclical variation in unemployment, and also quantitatively realistic changes in unemployment in response to changed policies. Unfortunately, as we showed in a previous paper (Costain and Reiter 2005), the standard matching model of Pissarides (2000) fails on this score. That model either underpredicts unemployment variation over the business cycle (if parameters are chosen so that the match surplus is large), or overpredicts unemployment variation in response to changes in the UI benefit (if parameters are chosen so that the match surplus is small). No parameterization can reproduce both these key aspects of unemployment variability.

Like Shimer (2004, 2005) and Hall (2005), we found that sticky wages could resolve this puzzle; but since microfoundations for sticky wages are controversial, we prefer a solution based on technology. As our earlier paper showed, it helps to allow for match-specific productivity. Concretely, we distinguish between "bad jobs" and "good jobs", and we assume that when aggregate productivity is high, more of the newly created jobs are good. ${ }^{7}$ To see why this helps us match the data, consider the extreme case in which aggregate technology shocks change the productivity of all new jobs, leaving that of existing jobs unchanged. Then a firm which hires in the good aggregate state expects its job to remain good until separation. Holding fixed the variance of aggregate productivity, this means the expected discounted profitability of a vacancy rises more in response to a positive shock in a model with a matchspecific productivity component than in the standard matching model where productivity is entirely "disembodied". Hiring and unemployment therefore vary more with the cycle.

Thus we have two margins along which we can adjust unemployment volatility. If we increase the importance of the match-specific productivity component relative to the aggregate component, cyclical unemployment variability rises without much change in the response of unemployment to the UI subsidy. If we

\footnotetext{
${ }^{7}$ In Costain and Reiter (2005), we assumed that in times of high (low) aggregate productivity, all new jobs are good (bad), and called this "embodied technical progress". The formulation in the present paper is somewhat more general.
} 
reparameterize to make the match surplus smaller, both aspects of unemployment volatility increase. Appropriate choices on both margins should permit the model to fit both cyclical and policy-related unemployment variations.

\section{Labor market}

We embed our match-specific productivity specification into a standard aggregate matching and bargaining setup. We assume a matching function with equal elasticities of unemployment and vacancies $(\lambda=0.5)$, in line with empirical evidence (see the literature review in Petrongolo and Pissarides 2001). To avoid introducing arbitrary inefficiencies, we likewise set workers' bargaining share to $\sigma=0.5$. Thus if fiscal policies were nondistortionary, and financial markets were perfect, our matching market would be efficient (Hosios 1991). The two remaining aggregate matching parameters are $\mu$ and $\kappa$, which we will set (conditional on all other technological parameters) to determine the unemployment and vacancy rates. We target an average unemployment rate of $6 \%$, typical of the postwar US. We set the vacancy rate so that firms fill vacancies with approximately probability 0.5 per month. This is just a normalization, since the ratio of vacancies to unemployment can be rescaled without consequences for the employment process. Technically, we only need to ensure that all transition probabilities are well below one.

\section{Productivity process}

We assume productivity has both aggregate and idiosyncratic components. Our parameterization of the "bad" and "good" idiosyncratic productivities is not intended to mimic specific labor market sectors: it only serves to reproduce the properties of aggregate unemployment volatility mentioned earlier. We set the transition probabilities $\pi_{12}$ and $\pi_{21}$ of the aggregate shock $Z$ to an annual rate of $1 / 3$, so that recessions and booms are equally likely and a full cycle averages six years. We denote idiosyncratic job quality by $z$, taking values $z=1$ (bad) or $z=2$ (good). We specify the productivity of a job as $y(z, Z)=1+a(z)+A(Z)$, where $a(z)=-0.15$ if $z=1$, and 0.15 if $z=2$, and where $A(Z)=-0.0075$ if $Z=Z^{1}$, and 0.0075 if $Z=Z^{2}$. This defines our goods numeraire by normalizing the (unweighted) average of a worker's monthly productivity to unity. 
We target an average fraction of good jobs equal to $2 / 3$, so that even though most new hires are in bad jobs, most ongoing jobs are good. We target an average job separation rate of 0.25 per year (in line, for example, with Shimer 2005), but we let good and bad jobs separate at different rates. We set the rate for bad jobs as high as $40 \%$ annually $\left(\delta^{b}=0.0416\right.$ per month), adjusting the rate for good jobs to match the above average $\left(\delta^{g}=0.0147\right.$ per month). We normalize the fraction of good hires in recessions to $\pi^{g}\left(Z^{1}\right)=0$. The parameters $\pi^{g}\left(Z^{2}\right)$ (the fraction of good hires in booms) and $p^{\text {prom }}$ (the probability of promotion from a bad to a good job) are chosen so that 1 ) on average, 2/3 of jobs are good; and 2) in good times, promotion is slightly more probable than finding a good job while unemployed, which ensures that the employed never quit to search for a better job. This results in $\pi^{g}\left(Z^{2}\right)=0.119$ and $p^{\text {prom }}=0.0238$ per month. These productivity and duration parameters attribute roughly half of the aggregate fluctuations in productivity to variations in job composition, and the other half to the disembodied productivity component, which is what we found worked best in Costain and Reiter (2005) to explain unemployment volatility.

\section{Within-period utility}

We choose a CRRA utility function, like much of the dynamic optimal taxation literature, but we include a Stone-Geary consumption minimum:

$$
u(c, 1-h)=\frac{\left[(c-\bar{c})(1-h)^{\alpha_{l}}\right]^{1-\gamma}}{1-\gamma}
$$

Chetty (2004), p.33, estimates a risk-aversion parameter for unemployed agents of 4.75. This seems very high in a pure CRRA function, but as Chetty and Szeidl (2004) argue, it becomes more plausible if we assume that households have some fixed expenditures (a mortgage, for instance) which are not much less than their income during unemployment. This is captured by the StoneGeary part of the utility function, which increases risk aversion in equilibrium for unemployed households, without imposing an unreasonably high degree of curvature $\gamma$ overall. We set $\gamma=2$ and $\bar{c}=0.2$ (around $20 \%$ of the marginal product of labor). 
We assume that working requires time $h(1)=h(2)=1 / 3$, while searching requires time $h(0)=1 / 10$. We choose $\alpha_{l}$ so that for the average worker, the flow of surplus resulting from having a job instead of being unemployed is about $25 \%$ of labor productivity. That is, $\alpha_{l}$ sets the size of the match surplus, which is the second of the two margins we use to control unemployment variability. This amount of surplus was found in Costain and Reiter (2005) to give the right response of unemployment to variation in UI, and still works well in the present, more complicated model.

Discounting and financial markets

We fix the interest rate by assuming that capitalists' annual discount rate is $R^{-1}=1.05^{-1}$. We assume that workers' liquidity constraint is $\underline{a}=0$. We choose workers' annual discount rate, $\beta=0.92$, taking into account the fact that a large fraction of workers have very low liquid asset holdings. In equilibrium this choice of $R$ and $\beta$ implies that they will accumulate liquid assets equal to a few months' wages.

\section{Fiscal policy}

We assume that government spending is $G=0.188$, roughly $20 \%$ of output, which is in line with US federal public expenditure. We set the baseline unemployment benefit level to $\bar{b}=0.32$, which implies a $40 \%$ replacement ratio in our static benchmark economy, close to the estimate of the average replacement ratio reported in Engen and Gruber (2001). The countercyclicality of the deficit, $\hat{X}$, and the countercyclicality of the unemployment benefit will be varied systematically to find the optimal policy regime.

\section{$7 \quad$ Simulation results}

\subsection{Benchmark results}

\subsubsection{Steady state}

The static benchmark economy is defined by setting the probability that new matches are good to its mean, $\bar{\pi}^{g} \equiv \frac{\pi_{21}}{\pi_{12}+\pi_{21}} \pi^{g}\left(Z^{1}\right)+\frac{\pi_{12}}{\pi_{12}+\pi_{21}} \pi^{g}\left(Z^{2}\right)=0.0595$, and likewise setting the aggregate component of productivity to $\frac{\pi_{21}}{\pi_{12}+\pi_{21}} A\left(Z^{1}\right)+$ 
$\frac{\pi_{12}}{\pi_{12}+\pi_{21}} A\left(Z^{2}\right)=0$. Static benchmark fiscal policy is just a constant unemployment benefit $\bar{b}_{0} \equiv 0.32$. This specification eliminates all aggregate uncertainty, so the economy converges to a steady state, described in Table 2 . In the steady state, the unemployment rate is $5.8 \%$, the monthly probability of finding a job is 0.389 , and two-thirds of those employed have good jobs. Output is 0.990 and the average product of labor is 1.050 . The wage is 0.840 in good jobs, and 0.729 in bad jobs. The tax on labor is $\tau=0.209$.

The asset distribution associated with this steady state (see Fig. 2) is the distribution $\bar{\Phi}$ at which we will evaluate all value functions. Likewise, the associated consumption distribution defines the baseline welfare level $\overline{\mathcal{V}}$ mentioned in Section 5. Mean assets are 2.402 (roughly three months' worth of wages), with standard deviation 0.961 . The distribution of consumption has mean 0.784 and standard deviation 0.078. On average, relative risk aversion is 2.704, while for the unemployed, mean relative risk aversion is 3.195.

The table further decomposes the distributions of assets and consumption. The consumption policy functions are graphed in Fig. 3, which shows that when a badly-employed worker with conditional mean assets 1.507 loses his job, his consumption falls by $22.1 \%$. For a worker in a good job, with conditional mean assets 2.911 , the fall in consumption is $25.6 \%$. Workers draw down their assets during unemployment; starting from the mean wealth of the employed, assets of the unemployed reach zero after roughly nine months.

\subsubsection{Costs of business cycles}

Table 3 describes the long-run average behavior of the dynamic benchmark equilibrium. This economy has the same parameters as the static benchmark, and the same fiscal policy $(\hat{X}=\hat{b}=0, \bar{b}=0.32)$, except that now the probability that a new job is good fluctuates between $\pi^{g}\left(Z^{1}\right)=0$ and $\pi^{g}\left(Z^{2}\right)=0.119$, and the aggregate productivity component fluctuates between $A\left(Z^{1}\right)=-0.0075$ and $A\left(Z^{2}\right)=0.0075$. In this economy, the mean unemployment rate is $6.0 \%$, falling to $5.4 \%$ conditional on good times, and rising to $6.5 \%$ in bad times. The monthly probability of job finding has mean 0.416 in a boom, and mean 0.338 in recession. Fig. 4 shows the resulting distribution of 
unemployment spell lengths in the dynamic benchmark and static benchmark economies. ${ }^{8}$ While the mean unemployment rate is only 1.2 times higher in recessions than in booms, the figure shows that the probability of remaining unemployed for nine months (long enough to run out of assets) is small, but is three times higher in recessions than in booms. Taking unconditional averages, the probability of remaining unemployed for nine months is fifty percent higher in the dynamic benchmark economy than in the static benchmark.

A second way that fluctuations increase risk for workers is that they increase wage variation, due to changes in the marginal product of labor and also in workers' threat points. The average wage in booms is 0.876 for good jobs and 0.755 for bad jobs, while in recessions it is 0.815 and 0.700 , respectively. Due to variation in unemployment and wages, we see in Table 3 that the cross-sectional average of consumption varies from 0.807 in booms to 0.771 in recessions. While mean consumption in the static economy was 0.832 in good jobs and 0.731 in bad jobs, in the dynamic economy it varies from 0.849 for those in good jobs in booms to 0.717 for those in bad jobs in recessions. In response to the increased risk, workers hold about $12 \%$ more wealth in the dynamic economy than they do in the static economy. Further details of the asset and consumption distributions are given in the table. ${ }^{9}$

Overall, cycles have several conflicting effects on workers' long-run welfare. Suffering greater risk, they build up more assets than in the static baseline economy. Greater assets give them a more advantageous position in wage bargaining, so the wage is $0.5 \%$ higher in this economy than in the static economy. With a higher wage, firms hire less, so the unemployment rate is 0.2 percentage points higher on average in the dynamic benchmark economy. In spite of the higher unemployment, workers' consumption is $0.6 \%$ higher

\footnotetext{
${ }^{8}$ The graph shows the probability distributions over spell lengths conditional on remaining in the good state, bad state, or static economy forever. These probabilities are simply powers of $1-p$, where $p$ is the probability of job finding.

${ }^{9}$ While the static benchmark economy converges to a steady state distribution $\bar{\Phi}$, the distribution $\Phi_{t}$ of the dynamic economy varies continually over time. Thus, for example, when Table 3 reports that the standard deviation of assets is 1.251 , this refers to the mean, over time, of the cross-sectional standard deviations of the distributions $\Phi_{t}$.
} 
on average than in the static economy, both because the wage is higher, and because they have more interest income.

All these issues affect the social welfare difference between the static and dynamic economies, but Tables 2 and 3 are not directly comparable since the statistics in Table 3 are evaluated at a higher level of assets. To isolate the effects of imposing productivity shocks, we should start the two economies from the same initial conditions: that is, we should include transition dynamics in our welfare measure. This is the welfare measure in equation (21) does, which can be interpreted as the cost of switching on the aggregate shocks, starting from the steady state $\bar{\Phi}$ of the static benchmark. Applying the formula in equation (21), we find that cycles impose a cost equivalent to $\Delta^{*}=-0.269 \%$ of baseline average consumption.

\subsubsection{Discussion}

This cost is quite large by the standards of Lucas (2003), who says he believes the gains from macroeconomic stabilization are probably "one or two orders of magnitude smaller" than $0.1 \%$ of consumption. For more perspective on the size our cost estimate, we can use Lucas' formula for an upper bound on the benefits of eliminating cycles in the representative agent case:

$$
\frac{1}{2} * \text { relative risk aversion } * \text { variance of } \log \text { consumption }
$$

In our simulation, average relative risk aversion is 2.7 , and total consumption (which is output minus vacancy costs) has a coefficient of variation of 0.018 , slightly less than the variability of output. Thus by Lucas' formula, the cost of cycles should be at most $0.5 * 2.7 *(0.018)^{2} \approx 0.043 \%$ of consumption, less than a sixth of the cost we calculate.

However, aggregate consumption is only part of the story, since it includes the consumption of the risk-neutral capitalists. In our economy, workers' consumption is substantially more variable, with a coefficient of variation of 0.033 . Using this higher measure of consumption variability, Lucas' bound implies welfare gains of at most $0.5 * 2.7 *(0.033)^{2} \approx 0.15 \%$ of consumption, roughly 
$55 \%$ of our estimate of the welfare gains from eliminating cycles. The high volatility of workers' consumption results from the even greater volatility of the wage, which has a coefficient of variation of $4.1 \%$, reflecting the deterioration of workers' bargaining position in recessions due to decreased assets and increased unemployment risk. Thus even though our model is calibrated to produce reasonable output fluctuations, it turns out to generate too much consumption risk for workers, due to the high degree of wage flexibility implied by Nash wage bargaining.

Another way to understand our cost estimate is to compare it to the potential benefits associated with variation in labor supply. In the absence of frictions, it would be beneficial in this "real business cycle" economy to work more when productivity is high and less when it is low. Fixing mean productivity and mean labor, the gain in mean output from making productivity vary by $\pm \epsilon_{y}$ between booms and recessions, and labor vary by $\pm \epsilon_{n}$ between booms and recessions, is $\epsilon_{y} \epsilon_{n}$. In the dynamic benchmark, $\epsilon_{y}=0.012$, and $\epsilon_{n}=0.006$. Eliminating this fluctuation (without changing means) would lower average output by $0.012 * 0.006=0.0072 \%$, or $0.0091 \%$ of consumption, tiny compared with our estimate of the cost of cycles.

In summary, we find that the welfare costs of cycles are modest, but are nonetheless around 30 times larger than the purported gains from making labor procyclical in a real business cycle context. We next ask how much of the welfare loss associated with cycles can be eliminated by fiscal policy.

\subsection{Optimal stabilization}

Fig. 5 is a contour plot of the social welfare function, for a variety of cyclical fiscal policies. ${ }^{10}$ Each contour line represents a change in welfare equivalent to $0.02 \%$ of static benchmark consumption. All policies considered in the graph fix mean unemployment insurance at $\bar{b}=0.32$. We vary the government's

\footnotetext{
${ }^{10}$ We calculate social welfare in simulated economies on a coarse grid over $\hat{X}$ and $\hat{b}$, then interpolate the welfare function by fitting a Chebyshev polynomial. The graph shows the indifference curves of the interpolated welfare function.
} 
deficit in recessions from $\hat{X}=0$ to $\hat{X}=0.08$ per capita (approximately $8 \%$ of output per worker). We also compare different degrees of time variation in UI benefits, ranging from $\hat{b}=-0.01$ (lowering benefits by $1 \%$ of output per worker in recessions) to $\hat{b}=0.04$ (raising benefits by $4 \%$ of output per worker in recessions).

The dynamic benchmark economy is at the origin in the graph. The optimal policy (conditional on mean benefits $\bar{b}$ ) has $\hat{X} \approx 0.05$ and $\hat{b} \approx-0.006$ : a countercyclical deficit of $5 \%$ of output per worker, and a slightly procyclical unemployment benefit. This optimal economy is described in Table 4. The optimal policy goes far beyond tax smoothing: taxes are strongly procyclical, at 0.256 in booms and only 0.161 in recessions. The graph also shows the curve of constant total distortions (equalizing the sum of average taxes plus benefits across recessions and booms, plotted by interpolating our simulation results). Note that the optimal policy is to the right of this curve, deep in the region of employment stabilization.

The procyclical tax policy at the optimum substantially smoothes unemployment, allowing lower precautionary saving. Mean unemployment in recessions is $6.1 \%$, while in booms it is $5.6 \%$; thus unemployment varies half as much as in the dynamic benchmark. Wages in good and bad jobs are 0.864 and 0.741 in recessions and 0.828 and 0.715 in booms. Average consumption is quite smooth: it is 0.791 in recessions and 0.786 in booms. ${ }^{11}$ Average consumption of the unemployed varies even less: 0.557 in recessions and 0.559 in booms. Average assets fall to 2.449 in the stabilized economy, $9 \%$ less than in the dynamic benchmark. The welfare differential of the stabilized economy, compared to the static benchmark, is $\Delta(0.05,-0.006,0.32)=-0.084 \%$ of static benchmark consumption. Stated differently, optimal stabilization of the dynamic benchmark economy increases welfare by $0.269 \%-0.084 \%=0.185 \%$ of consumption. Thus, around seventy percent of the welfare cost of business cycles is eliminated by stabilization.

\footnotetext{
${ }^{11}$ Thus taxes vary so much that average consumption becomes countercyclical. But Fig. 5 shows by interpolation that the optimum actually lies between $(\hat{X}=0.05, \hat{b}=-0.006)$ and $(\hat{X}=0.04, \hat{b}=-0.003)$, where consumption is mildly procyclical. Thus average consumption at the exact optimum is likely to be very close to constant. On the other hand, (after tax) wages are countercyclical at both $(\hat{X}=0.05, \hat{b}=-0.006)$ and $(\hat{X}=0.04, \hat{b}=-0.003)$.
} 


\subsubsection{Discussion}

A simple way to understand the welfare effects of stabilizing fiscal policy is just to count contour lines in the graph, decomposing the gains by looking at the curve of constant distortions. Only a small part of the overall welfare improvement comes from moving rightwards from the dynamic benchmark to the point of $\operatorname{tax}$ (and benefit) smoothing, which is $\hat{X} \approx 0.005$. Table 9 shows that tax smoothing reduces the welfare loss associated with business cycles from $0.269 \%$ to $0.243 \%$ of baseline average consumption.

More than half the welfare gain occurs as we move northeast along the curve of constant distortions, which represents passing along lump-sum insurance payments against the aggregate shock to the workers. The best policy along this curve lies at $\hat{X} \approx 0.03$ and $\hat{b} \approx 0.02$. Since distortions are constant over the cycle, the countercyclical deficit fails to stabilize employment in this case: unemployment is 1.3 percentage points higher in recessions than in booms, similar to the variation in the dynamic benchmark. This policy's value is reported in Table 9 under the heading "Aggregate insurance": the welfare loss from business cycles falls to only $0.133 \%$ of baseline consumption. In principle, part of this improvement could be achieved by private markets selling insurance against aggregate shocks. However, in an economy lacking such markets, one reason the government might prefer a deficit in recessions would be to finance insurance payments to the public against the aggregate shock.

But intuitively, fair insurance payments against the aggregate shock are a blunt instrument for smoothing individual consumption. Such payments are harmful for the unemployed in booms, since their benefits are decreased. It is better for the government to pass along the revenue from the deficit it runs in recession by cutting taxes and maintaining benefits fixed, instead of simply paying it out as a lump-sum transfer. As we move down off the line of constant distortions to the optimal point $\hat{X} \approx 0.05, \hat{b} \approx-0.006$, another quarter of the welfare gains accrue, reducing the cost of cycles to just $0.084 \%$ of baseline consumption. This optimal policy is strongly stabilizing: total distortions are much lower in recessions, so that unemployment is only 0.5 percentage points higher in recessions than in booms, and consumption is almost completely smoothed over the cycle, especially for the unemployed. 


\subsection{Robustness}

\subsubsection{Changing unemployment insurance}

We next consider the effects of changing the mean level of the unemployment benefit. Tables 5-8 compare the effects of lowering mean UI to $\bar{b}=0.30$ (a replacement ratio of $37 \%$ ), and raising it to $\bar{b}=0.34$ (replacement ratio $42 \%)$. In both cases, policy is acyclical $(\hat{X}=\hat{b}=0)$. Higher UI increases total labor market distortions, so unemployment rises from $5.7 \%$ to $6.3 \%$ as $\bar{b}$ increases. These numbers imply a semielasticity of unemployment with respect to the replacement ratio of 2.0. This exceeds Layard and Nickell's (1999) point estimate of 1.3 , but is inside their $95 \%$ confidence interval.

We see many other signs of greater efficiency as UI decreases. Taxes fall from 0.213 when $\bar{b}=0.34$ to 0.207 with $\bar{b}=0.30$. With the same change, output rises by $0.7 \%$, and wages rise by $0.6 \%$. In other words, even though lower UI, by itself, worsens the worker's bargaining position, it has a strong enough effect on unemployment that (after tax) wages rise in equilibrium. Also, average consumption rises by $0.76 \%$, and the variation in average consumption between recessions and booms is essentially unchanged. On the other hand, lower benefits force workers to save more; they increase their buffer stocks of assets by $12 \%$ as $\bar{b}$ decreases from 0.34 to 0.3 . This rise in assets partially explains the increases in long run average consumption and wages.

In Table 10, these efficiency gains are reflected in welfare. Total social welfare in the economy with cycles, and policy $(\hat{X}=\hat{b}=0, \bar{b}=0.30)$, is only $0.152 \%$ lower than in the static benchmark. In other words, welfare improves substantially relative to the dynamic benchmark of $\bar{b}=0.32$. The gain is unevenly distributed: the unemployed are slightly worse off with $\bar{b}=0.30$ than with $\bar{b}=0.32$, but workers as a whole are better off, as are capitalists. Thus the distortionary effects of unemployment insurance are quite harmful in this economy. We have computed equilibria with UI subsidies from $\bar{b}=0.24$ to $\bar{b}=0.36$ (not reported in the tables). Over this whole range, total social welfare is decreasing (and concave) in $\bar{b}$. On the other hand, from the point of 
view of an initially unemployed agent, the preferred benefit level is $\bar{b}=0.32$, and an agent who is initially employed in a bad job prefers $\bar{b}=0.28$.

Regardless of the mean level of UI, we always find that stabilizing the economy yields further welfare gains. Moreover, stabilization benefits all three classes of workers, as well as capitalists. The effects on unemployment, wages, asset holdings, and consumption are similar to those we found for $\bar{b}=0.32$. The welfare impact of stabilization is analyzed in Table 10 . With $\bar{b}=0.30$, stabilization raises welfare from $\Delta(0,0,0.30)=-0.152 \%$ to $\Delta(0.05,-0.003,0.30)=$ $+0.046 \%$. Quantitatively, the optimal countercyclical deficit varies little as $\bar{b}$ changes; it always lies between $4 \%$ and $5 \%$ of output per worker, as Figures 6 a and $6 \mathrm{~b}$ show for $b=0.30$ and $b=0.34$. However, it does decrease mildly with benefits: the optimal countercyclical deficit is closer to $5 \%$ for our simulations with $\bar{b} \geq 0.32$, and is closer to $4 \%$ for $\bar{b} \leq 0.30$. Thus, we find some evidence that stabilization policy and unemployment insurance are substitutes, but the quantitative interaction is not strong.

\subsubsection{Changing preference parameters}

It is reasonable to believe that the welfare effects of stabilization could vary with agents' ability to insure against idiosyncratic shocks, and also with their sensitivity to risk. Therefore we recompute our model raising $\gamma$ to 3 , which raises mean relative risk aversion to 4.043 in equilibrium, with conditional mean 4.765 for the unemployed, close to the estimate of Chetty (2004).

Setting the UI benefit to $\bar{b}=0.32$, we calculate the cost of business cycles as we did in section 7.1.2. ${ }^{12}$ With $\gamma=3$, the welfare cost of business cycles is moderately larger than in our benchmark calculation; the loss due to cycles is $0.322 \%$ of consumption. Workers avoid larger welfare losses by increasing their wealth $27 \%$ compared with our benchmark simulations; mean wealth in the static economy with $\gamma=3$ is 3.052, close to four months' wages. Meanwhile, the optimal cyclical policy is more or less unchanged. Again, a countercyclical

\footnotetext{
${ }^{12}$ That is, we compare a static economy with $\gamma=3$ and $\bar{b}=0.32$ to a fluctuating economy with $\gamma=3$ and fiscal policy $\hat{X}=0, \hat{b}=0, \bar{b}=0.32$, expressing the difference as a percentage of consumption in the static economy.
} 
deficit of between $4 \%$ and $5 \%$ of output per capita is optimal, while the UI benefit should be more or less acyclical.

Similar policy implications are obtained when we make the capitalists more patient, which lowers the interest rate to two percent $(R=1.02)$. A lower interest rate (leaving workers' patience unchanged) makes precautionary saving more costly, so workers' mean assets fall to just 1.438. Therefore, workers are more exposed to risk than in the benchmark simulation, so the cost of business cycles rises to $0.367 \%$ of consumption. ${ }^{13}$ However, the optimal policy is roughly the same as before, with $\hat{X} \approx 0.04$ and $\hat{b} \approx 0$, which reduces the loss from cycles to only $0.112 \%$ of consumption. The social welfare functions for $\gamma=3$ and $R=1.02$ are shown in the last two panels of Fig. 6 .

\subsubsection{Discussion}

The striking observation about all our policy exercises is how little the optimal cyclical policy changes. UI benefits should be close to constant in all cases, while taxes should be strongly procyclical, requiring a countercyclical deficit of four to five percent of output. As expected, fluctuations are more costly when risk aversion is higher or when precautionary saving is lower, though the difference in welfare costs is not that large. We also find slightly lower optimal countercyclicality of the deficit when UI is more generous.

A reasonable explanation for the robustness of the optimal cyclical policy is that, as we mentioned earlier, the output gains from making labor procyclical are extremely small. These gains are so much smaller than the utility losses from fluctuation in workers' consumption that there is little tradeoff between the two; the main issue for the government is just reducing consumption fluctuation. Therefore, all our simulations show that the optimal cyclical policy is one that comes close to holding average consumption, and especially the consumption of the unemployed, constant over the cycle. The amount of

\footnotetext{
${ }^{13}$ This statement compares a static economy with $R=1.02$ and $\bar{b}=0.32$ to a fluctuating economy with $R=1.02$ and fiscal policy $\hat{X}=0, \hat{b}=0, \bar{b}=0.32$, expressing the difference as a percentage of consumption in the static economy.
} 
variation in labor market distortions that achieves this depends mostly on technology and on the wage determination framework, not on parameters related to precautionary saving or risk aversion. Therefore increasing risk aversion, for example, increases the welfare gain from eliminating business cycles, but has little effect on the optimal cyclical policy.

\section{Conclusions}

This paper has constructed a model to capture the aggregate and idiosyncratic income fluctuations that make business cycles costly. Productivity shocks drive fluctuations in output and employment. The labor income process is determined by a matching technology and a wage bargaining game. Risk averse workers try to smooth away their labor income risk through precautionary saving. We parameterize the model to reproduce both the cyclical and policyrelated variation in unemployment. In this framework, switching on aggregate shocks increases unemployment risk and wage variability. Therefore, business cycles decrease social welfare, by an amount equivalent to diminishing all workers' consumption by $0.269 \%$.

We assume the government can pay unemployment benefits financed by labor income taxes, and we characterize the optimal degree of cyclicality in benefits, taxes, and the government deficit. We report two main results. First, we find that the government should vary tax rates aggressively to reduce the fluctuation in the unemployment rate, average wages, and average consumption. In our benchmark specification, the tax rate in booms should be around one and a half times that in recessions. Second, we show that smoothing the cycle in this way eliminates most of the cost of business cycles. One reason smoothing is effective is that it has little downside in our model: the efficiency loss from eliminating the positive correlation between employment and labor productivity is tiny. In summary, this means that even an economy with "real business cycles" should be stabilized, if capital markets are imperfect.

While optimal taxes are highly variable, the optimal UI benefit remains roughly constant over the cycle, to avoid imposing unusually severe costs on 
the unemployed at any point in time. Therefore, the procyclicality of the optimal tax policy requires a strongly countercyclical deficit, around 5\% of output in our benchmark simulation. As for the mean level of unemployment benefits, we find that workers' preferences vary substantially with their initial employment state. However, given our US-style benchmark replacement ratio of $40 \%$, a decrease in benefits raises total social welfare. Finally, we also show that with lower UI, optimal stabilization policy is slightly more aggressive. But this substitutability is quite weak, which is part of the reason why our findings about optimal cyclical fiscal policy are so robust.

\section{REFERENCES}

Aiyagari, Rao; Albert Marcet; Thomas Sargent; and Juha Seppala (2002), "Optimal Taxation without State-Contingent Debt." Journal of Political Economy 110, pp. 1220-54.

Atkeson, Andrew, and Christopher Phelan (1994), "Reconsidering the Costs of Business Cycles with Incomplete Markets." NBER Macroeconomics Annual 1994, pp. 187-207.

Barro, Robert (1979), "On the Determination of the Public Debt." Journal of Political Economy 87, pp. 940-71.

Beaudry, Paul, and Carmen Pagés (2001), "The Cost of Business Cycles and the Stabilization Value of Unemployment Insurance." European Economic Review 45 (8), pp. 1545-72.

Chari, V. V.; Lawrence Christiano; and Patrick Kehoe (1994), "Optimal Fiscal Policy in a Business Cycle Model." Journal of Political Economy 102 (4), pp. 617-52.

Chetty, Raj (2004), "Optimal Unemployment Insurance when Income Effects are Large." NBER Working Paper \#10500.

Chetty, Raj, and Adam Szeidl (2004), "Consumption commitments: neoclassical foundations for formation." NBER Working Paper \#10970.

Costain, James, and Michael Reiter (2005), "Business Cycles, Unemployment Insurance, and the Calibration of Matching Models." Univ. Pompeu Fabra Economics Working Paper \#862. 
Den Haan, Wouter (1997), "Solving Dynamic Models with Aggregate Shocks and Heterogeneous Agents." Macroeconomic Dynamics 1 (2) pp. 355-86.

Engen, Eric, and Jonathan Gruber (2001), "Unemployment insurance and precautionary saving." Journal of Monetary Economics 47 (3), pp. 545-79.

Gomes, João, Jeremy Greenwood, and Sergio Rebelo (2000), "Equilibrium Unemployment." Journal of Monetary Economics 48, pp. 109-52.

Greenwood, Jeremy, and Gregory Huffman (1991), "Tax Analysis in a RealBusiness-Cycle Model: On Measuring Harberger Triangles and Okun Gaps." Journal of Monetary Economics 27 pp. 167-90.

Hall, Robert (2005), "Employment Fluctuations with Equilibrium Wage Stickiness." American Economic Review 95 (1), pp. 50-65.

Hosios, Arthur (1990), "On the Efficiency of Matching and Related Models of Search and Unemployment." Review of Economic Studies 57 (2) pp. 279-98.

Imrohoroglu, Ayse (1989), "The Cost of Business Cycles with Indivisibilities and Liquidity Constraints." Journal of Political Economy 97 pp. 1364-83.

Krebs, Tom (2003), "Growth and Welfare Effects of Business Cycles in Economies with Idiosyncratic Human Capital Risk." Review of Economic Dynamics 6 (4), pp. 846-68.

Krebs, Tom (2004), "Welfare Cost of Business Cycles When Markets Are Incomplete." Brown Univ. Economics Working Paper \#2004-08.

Krusell, Per, and Anthony A. Smith (1998), "Income and Wealth Heterogeneity in the Macroeconomy." Journal of Political Economy 106 (5) pp. 243-77.

Krusell, Per, and Anthony A. Smith (1999), "On the Welfare Effects of Eliminating Business Cycles." Review of Economic Dynamics 2 (1) pp. 245-72.

Layard, Richard, and Stephen Nickell (1999), "Labor Market Institutions and Economic Performance." In Orley Ashenfelter and David Card, eds., Handbook of Labor Economics, v. 3c. Amsterdam: North-Holland.

Lucas, Robert E., and Nancy Stokey (1983), "Optimal Fiscal and Monetary Policy in an Economy without Capital." Journal of Monetary Economics 12 , pp. 55-93.

Lucas, Robert E. (1987), Models of Business Cycles, Basil Blackwell.

Lucas, Robert E. (2003), "Macroeconomic Priorities." American Economic Review, 93 (1), pp. 1-14.

Petrongolo, Barbara, and Christopher Pissarides (2001), "Looking into the Black Box: a Survey of the Matching Function", Journal of Economic Literature 39 (2), pp. 390-431. 
Pissarides, Christopher (1991), Equilibrium Unemployment Theory. Basil Blackwell.

Reiter, Michael (2002), "Recursive Solution of Heterogeneous Agent Models." Manuscript, Univ. Pompeu Fabra.

Schmitt-Grohe, Stephanie, and Martin Uribe (2004), "Optimal Fiscal and Monetary Policy under Imperfect Competition." Journal of Macroeconomics 26 (2), pp. 183-209.

Shimer, Robert (2004), "The Consequences of Rigid Wages in Search Models." Journal of the European Economic Association (Papers and Proceedings) 2 (2-3), pp. 469-79.

Shimer, Robert (2005), "The Cyclical Behavior of Equilibrium Unemployment and Vacancies." American Economic Review 95 (1), pp. 25-49.

Storesletten, Kjetil, Chris Telmer, and Amir Yaron (2001), "The Welfare Costs of Business Cycles Revisited: Finite Lives and Cyclical Variation in Idiosyncratic Risk." European Economic Review 45 (7), pp. 1311-39. 
Table 1: Parameters.

\begin{tabular}{|c|c|c|}
\hline \multicolumn{3}{|l|}{ Aggregate shocks } \\
\hline Shock arrival rate & $\pi_{12}=\pi_{21}$ & $1-(2 / 3)^{(1 / 12)}$ \\
\hline \multicolumn{3}{|l|}{ Parameters of worker's problem } \\
\hline Credit constraint & $\bar{a}$ & 0 \\
\hline Discount factor & $\beta$ & 0.92 \\
\hline Relative risk aversion & $\gamma$ & 2 \\
\hline Essential consumption & $\underline{c}$ & 0.2 \\
\hline Value-of-time parameter & $\bar{\alpha}_{l}$ & 1.983 \\
\hline Time cost working & $h(1)=h(2)$ & $1 / 3$ \\
\hline Time cost searching & $h(0)$ & 0.1 \\
\hline \multicolumn{3}{|l|}{ Parameters of capitalist's problem } \\
\hline Interest rate & $R-1$ & 0.05 \\
\hline Vacancy cost & $\kappa$ & 0.2824 \\
\hline Productivity variation good/bad match & $a(z)$ & \pm 0.15 \\
\hline Productivity variation boom/recession & $A(Z)$ & \pm 0.0075 \\
\hline \multicolumn{3}{|l|}{ Matching and bargaining parameters } \\
\hline Matching function coefficient & $\mu$ & 0.4308 \\
\hline Unemployment elasticity of matching & $\lambda$ & 0.5 \\
\hline Worker's bargaining share & $\sigma$ & 0.5 \\
\hline Probability of good match in recessions & $\pi^{g}\left(Z^{1}\right)$ & 0 \\
\hline Probability of good match in booms & $\pi^{g}\left(Z^{2}\right)$ & 0.119 \\
\hline Prob. of promotion to good match & $p^{\text {prom }}$ & 0.0238 \\
\hline Separation rate of bad matches & $\delta^{b}$ & 0.0416 \\
\hline Separation rate of good matches & $\delta^{g}$ & 0.0147 \\
\hline \multicolumn{3}{|l|}{ Fiscal policy parameters } \\
\hline Government spending & $G$ & 0.188 \\
\hline Other policy parameters & $\bar{b}, \hat{b}, \hat{X}$ & variable \\
\hline
\end{tabular}


Table 2: Static benchmark equilibrium.

\begin{tabular}{llr}
\hline Employment and output: & & \\
Unemployment benefit & $\overline{1}$ & 0.32 \\
Tax rate & $\tau$ & 0.209 \\
Unemployment & $N^{b}$ & 0.058 \\
Employment in bad jobs & $N^{g}$ & 0.314 \\
Employment in good jobs & $N^{b} y(1)+N^{g} y(2)$ & 0.628 \\
Output & $\left(N^{b} y(1)+N^{g} y(2)\right) / N$ & 0.990 \\
Average product of labor & $w$ & 1.050 \\
Average wage & & 0.803 \\
Workers' asset distribution: ${ }^{1}$ & & \\
Mean & & 2.402 \\
Standard deviation & & 0.961 \\
Mean, for unemployed & & 1.728 \\
St. dev., for unemployed & 0.953 \\
Mean, employed in bad jobs & 1.507 \\
St. dev., employed in bad jobs & 0.642 \\
Mean, employed in good jobs & & 2.911 \\
St. dev., employed in good jobs & & 0.803 \\
Workers' consumption distribution: & & \\
Mean & & 0.784 \\
Standard deviation & 0.078 \\
Mean of relative risk aversion & 2.755 \\
Mean consumption, for unemployed & 0.552 \\
St. dev., for unemployed & 0.065 \\
Mean, employed in bad jobs & 0.731 \\
St. dev., employed in bad jobs & 0.028 \\
Mean, employed in good jobs & 0.832 \\
St. dev., employed in good jobs & 0.017 \\
\hline 1 Assets as multiple of numeraire. &
\end{tabular}

${ }^{1}$ Assets as multiple of numeraire. 
Table 3: Dynamic benchmark equilibrium.

\begin{tabular}{lccc}
\hline & Mean, overall & Mean, recession & Mean, boom \\
Employment and output: & & & \\
Unemployment benefit & 0.32 & 0.32 & 0.32 \\
Government deficit & 0 & 0 & 0 \\
Tax rate & 0.210 & 0.215 & 0.204 \\
Unemployment & 0.060 & 0.065 & 0.054 \\
Employment in bad jobs & 0.313 & 0.325 & 0.301 \\
Employment in good jobs & 0.627 & 0.610 & 0.645 \\
Output & 0.988 & 0.970 & 1.005 \\
Average product of labor & 1.050 & 1.038 & 1.062 \\
Average wage & 0.807 & 0.775 & 0.838 \\
Workers' asset distribution: & & & \\
Mean & 2.680 & 2.432 & 2.927 \\
Standard deviation & 1.251 & 1.172 & 1.329 \\
Mean, for unemployed & 1.975 & 1.750 & 2.200 \\
St. dev., for unemployed & 1.225 & 1.135 & 1.316 \\
Mean, employed in bad jobs & 1.726 & 1.555 & 1.896 \\
St. dev., employed in bad jobs & 0.880 & 0.817 & 0.942 \\
Mean, employed in good jobs & 3.215 & 2.967 & 3.462 \\
St. dev., employed in good jobs & 1.084 & 1.005 & 1.162 \\
Workers' consumption distribution: & & & \\
Mean & 0.789 & 0.771 & 0.807 \\
Standard deviation & 0.079 & 0.084 & 0.073 \\
Mean, for unemployed & 0.563 & 0.541 & 0.584 \\
St. dev., for unemployed & 0.065 & 0.067 & 0.063 \\
Mean, employed in bad jobs & 0.737 & 0.717 & 0.756 \\
St. dev., employed in bad jobs & 0.032 & 0.033 & 0.030 \\
Mean, employed in good jobs & 0.837 & 0.824 & 0.849 \\
St. dev., employed in good jobs & 0.020 & 0.021 & 0.020 \\
\hline Welfare, compared to static benchmark: & $\boldsymbol{N}^{*}=-\mathbf{0 . 2 6 9 \%}$ of consumption. \\
\hline
\end{tabular}

${ }^{1}$ Assets as multiple of numeraire. 
Table 4: Equilibrium under optimal stabilization.

\begin{tabular}{|c|c|c|c|}
\hline \multicolumn{4}{|l|}{ Employment and output: } \\
\hline Unemployment benefit & 0.320 & 0.314 & 0.326 \\
\hline Government deficit & 0 & 0.050 & -0.050 \\
\hline Tax rate & 0.208 & 0.161 & 0.256 \\
\hline Unemployment & 0.059 & 0.061 & 0.056 \\
\hline Employment in bad jobs & 0.314 & 0.330 & 0.300 \\
\hline Employment in good jobs & 0.627 & 0.609 & 0.645 \\
\hline Output & 0.988 & 0.974 & 1.003 \\
\hline Average product of labor & 1.050 & 1.037 & 1.062 \\
\hline Average wage & 0.807 & 0.821 & 0.792 \\
\hline \multicolumn{4}{|l|}{ Workers' asset distribution: ${ }^{1}$} \\
\hline Mean & 2.449 & 2.595 & 2.303 \\
\hline Standard deviation & 1.161 & 1.218 & 1.105 \\
\hline Mean, for unemployed & 1.767 & 1.859 & 1.674 \\
\hline St. dev., for unemployed & 1.132 & 1.184 & 1.080 \\
\hline Mean, employed in bad jobs & 1.546 & 1.649 & 1.443 \\
\hline St. dev., employed in bad jobs & 0.787 & 0.825 & 0.749 \\
\hline Mean, employed in good jobs & 2.974 & 3.186 & 2.762 \\
\hline \multicolumn{4}{|c|}{ Workers' consumption distribution: } \\
\hline Mean & 0.788 & 0.791 & 0.786 \\
\hline Standard deviation & 0.079 & 0.081 & 0.077 \\
\hline Mean, for unemployed & 0.558 & 0.557 & 0.559 \\
\hline St. dev., for unemployed & 0.067 & 0.068 & 0.066 \\
\hline Mean, employed in bad jobs & 0.735 & 0.739 & 0.730 \\
\hline St. dev., employed in bad jobs & 0.031 & 0.031 & 0.031 \\
\hline Mean, employed in good jobs & 0.837 & 0.842 & 0.831 \\
\hline St. dev., employed in good jobs & 0.020 & 0.019 & 0.020 \\
\hline
\end{tabular}

${ }^{1}$ Assets as multiple of numeraire. 
Table 5: Equilibrium with lower UI.

Mean, overall Mean, recession Mean, boom

Employment, output, and assets:

Unemployment benefit

0.30

0

0.30

0.30

Government deficit

0.207

0

0

Tax rate

0.057

0.212

0.202

Unemployment

0.991

0.062

0.052

Output

0.809

0.974

1.007

Average wage

2.840

0.777

0.840

Workers' mean assets ${ }^{1}$

2.589

3.091

Workers' consumption distribution:

Mean

0.792

0.774

0.810

Standard deviation

0.078

0.083

0.073

Mean, for unemployed

0.564

0.542

0.586

Mean, employed in bad jobs

0.738

0.719

0.758

Mean, employed in good jobs

0.839

0.827

0.852

Welfare, compared to static benchmark: $\mathbf{- 0 . 1 5 2 \%}$ of consumption.

Table 6: Lower UI, with stabilization.

Mean, overall Mean, recession Mean, boom

Employment, output, and assets:

Unemployment benefit

0.30

0.297

0.303

Government deficit

0

0.05

$-0.05$

Tax rate

0.206

0.159

0.253

Unemployment

0.056

0.058

0.053

Output

0.991

0.977

1.006

Average wage

0.809

0.823

0.794

Workers' mean assets ${ }^{1}$

2.609

2.756

2.461

Workers' consumption distribution:

Mean

0.791

0.794

0.788

Standard deviation

0.079

0.081

0.077

Mean, for unemployed

0.559

0.559

0.560

Mean, employed in bad jobs

0.736

0.741

0.731

Mean, employed in good jobs

0.839

0.844

0.833

Welfare, compared to static benchmark: $\mathbf{+ 0 . 0 4 6 \%}$ of consumption.

${ }^{1}$ Assets as multiple of numeraire. 
Table 7: Equilibrium with higher UI.

Mean, overall Mean, recession Mean, boom

Employment, output, and assets:

Unemployment benefit

0.34

0

0.34

0

0.34

Government deficit

0.213

0.219

0

Tax rate

0.063

0.070

0.207

Unemployment

0.984

0.966

0.057

Output

0.804

0.773

1.002

Average wage

2.539

2.294

0.835

Workers' mean assets ${ }^{1}$

0.786

0.768

2.785

Workers' consumption distribution:

Mean

0.079

0.084

0.804

Standard deviation

0.561

0.540

0.073

Mean, for unemployed

0.735

0.716

0.583

Mean, employed in bad jobs

0.834

0.821

0.754

Mean, employed in good jobs

Welfare, compared to static benchmark: $\mathbf{- 0 . 4 8 8 \%}$ of consumption.

Welfare, compared to static benchmark: $\mathbf{- 0 . 4 8 8 \%}$ of consumption.

0.846

Table 8: Higher UI, with stabilization.

Mean, overall Mean, recession Mean, boom

Employment, output, and assets:

Unemployment benefit

0.34

0.337

0.343

Government deficit

0

0.04

$-0.04$

Tax rate

0.212

0.175

0.248

Unemployment

0.062

0.065

0.058

Output

0.985

0.970

1.000

Average wage

0.804

0.810

0.799

Workers' mean assets ${ }^{1}$

2.264

2.333

2.194

Workers' consumption distribution:

Mean

0.785

0.783

0.786

Standard deviation

0.079

0.082

0.077

Mean, for unemployed

0.556

0.552

0.561

Mean, employed in bad jobs

0.733

0.733

0.732

Mean, employed in good jobs

0.834

0.835

0.832

Welfare, compared to static benchmark: $\mathbf{- 0 . 2 6 0 \%}$ of consumption.

${ }^{1}$ Assets as multiple of numeraire. 
Table 9: Stabilization policy and social welfare.

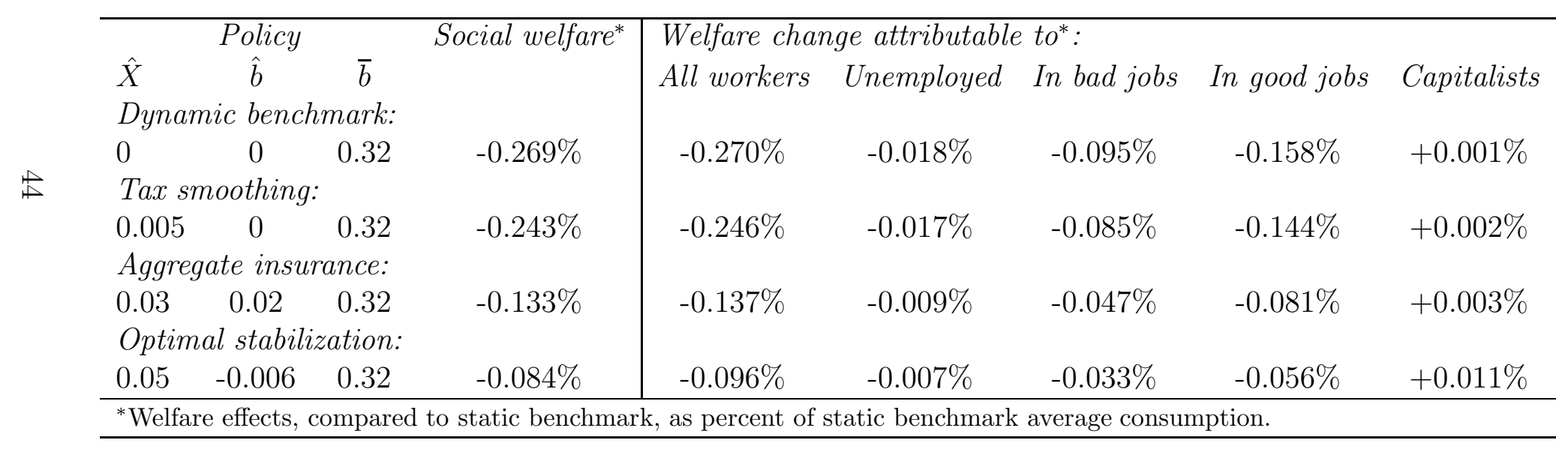


Table 10: Robustness of welfare effects.

\begin{tabular}{|c|c|c|c|c|c|c|c|c|}
\hline \multicolumn{3}{|c|}{ Parameters } & \multirow[t]{2}{*}{ Social welfare } & \multicolumn{5}{|c|}{ Welfare change attributable to: } \\
\hline$\hat{X}$ & $\hat{b}$ & $\bar{b}$ & & All workers & Unemployed & In bad jobs & In good jobs & Capitalists \\
\hline \multicolumn{9}{|c|}{ Lower UI*: } \\
\hline 0 & 0 & 0.3 & $-0.152 \%$ & $-0.208 \%$ & $-0.020 \%$ & $-0.082 \%$ & $-0.106 \%$ & $+0.057 \%$ \\
\hline \multicolumn{9}{|c|}{ Lower UI, with stabilization*: } \\
\hline 0.005 & -0.003 & 0.3 & $+0.046 \%$ & $-0.020 \%$ & $-0.008 \%$ & $-0.016 \%$ & $+0.004 \%$ & $+0.066 \%$ \\
\hline \multicolumn{9}{|c|}{ Higher $U I^{*}$ : } \\
\hline 0 & 0 & 0.34 & $-0.488 \%$ & $-0.429 \%$ & $-0.023 \%$ & $-0.140 \%$ & $-0.268 \%$ & $-0.059 \%$ \\
\hline \multicolumn{9}{|c|}{ Higher UI, with stabilization*: } \\
\hline 0.04 & -0.003 & 0.34 & $-0.260 \%$ & $-0.211 \%$ & $-0.009 \%$ & $-0.063 \%$ & $-0.139 \%$ & $-0.049 \%$ \\
\hline \multicolumn{9}{|c|}{ Higher risk aversion $(\gamma=3)^{a}$ : } \\
\hline 0 & 0 & 0.32 & $-0.322 \%$ & $-0.323 \%$ & $-0.023 \%$ & $-0.120 \%$ & $-0.181 \%$ & $+0.002 \%$ \\
\hline \multicolumn{9}{|c|}{ Higher $\gamma$, with stabilization ${ }^{a}$ : } \\
\hline 0.05 & 0 & 0.32 & $-0.059 \%$ & $-0.069 \%$ & $-0.005 \%$ & $-0.025 \%$ & $-0.038 \%$ & $+0.010 \%$ \\
\hline \multicolumn{9}{|c|}{ Lower interest rate $(R=1.02)^{b}$ : } \\
\hline 0 & 0 & 0.32 & $-0.367 \%$ & $-0.368 \%$ & $-0.023 \%$ & $-0.126 \%$ & $-0.221 \%$ & $+0.001 \%$ \\
\hline \multicolumn{9}{|c|}{ Lower $R$, with stabilization ${ }^{b}$ : } \\
\hline 0.04 & 0 & 0.32 & $-0.112 \%$ & $-0.123 \%$ & $-0.008 \%$ & $-0.043 \%$ & $-0.073 \%$ & $+0.011 \%$ \\
\hline
\end{tabular}

${ }^{*}$ Welfare effects, compared to static benchmark, as percent of static benchmark average consumption.

${ }^{a}$ Welfare effects, compared to static economy with $\gamma=3, R=1.05, \bar{b}=0.32$, as percent of that economy's average consumption.

${ }^{b}$ Welfare effects, compared to static economy with $\gamma=2, R=1.02, \bar{b}=0.32$, as percent of that economy's average consumption. 
Fig. 1: Policy space, conditional on average UI benefits

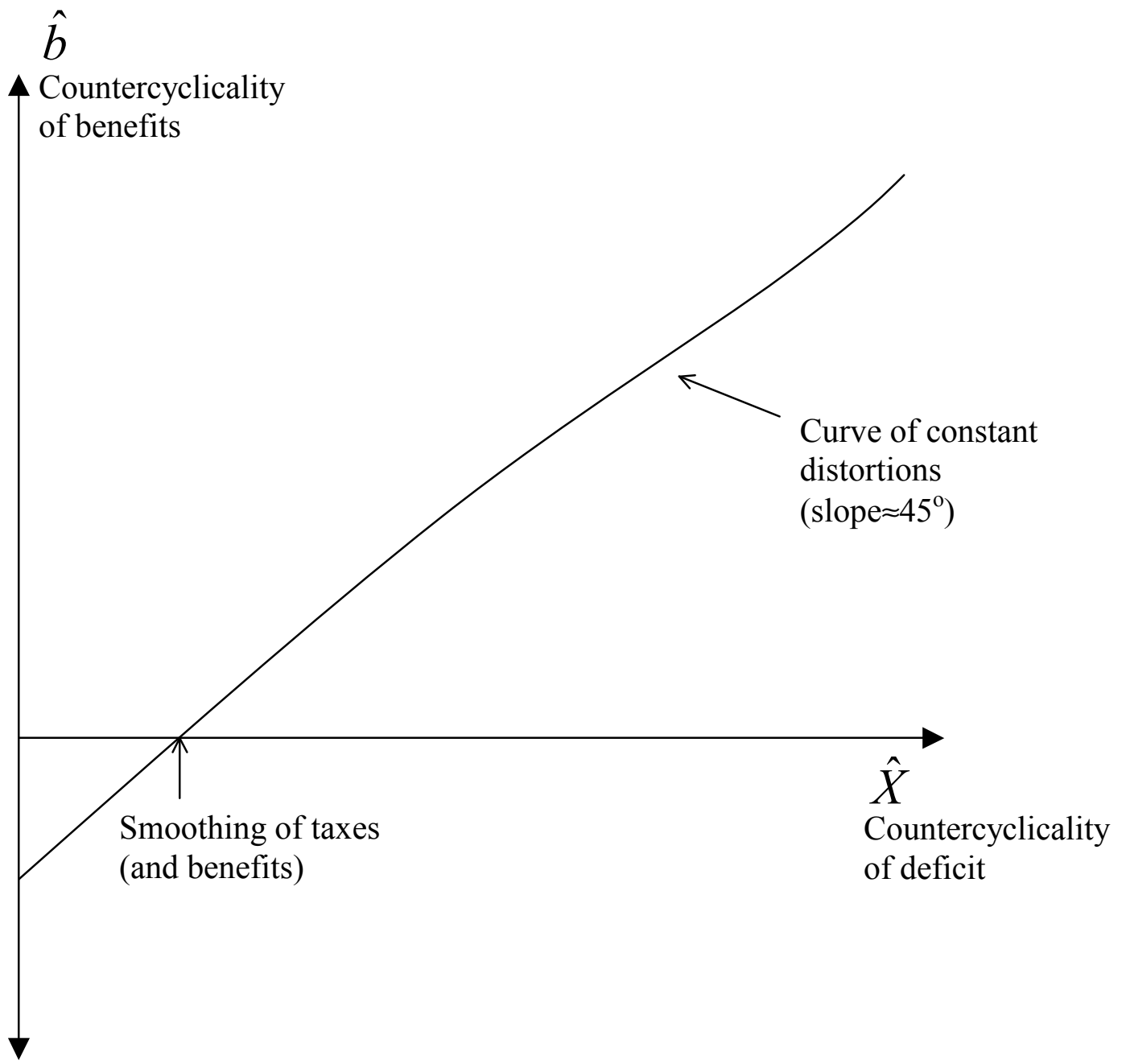


Fig. 2: Assets of unemployed (solid), bad employed (dash), good employed (dash dot)

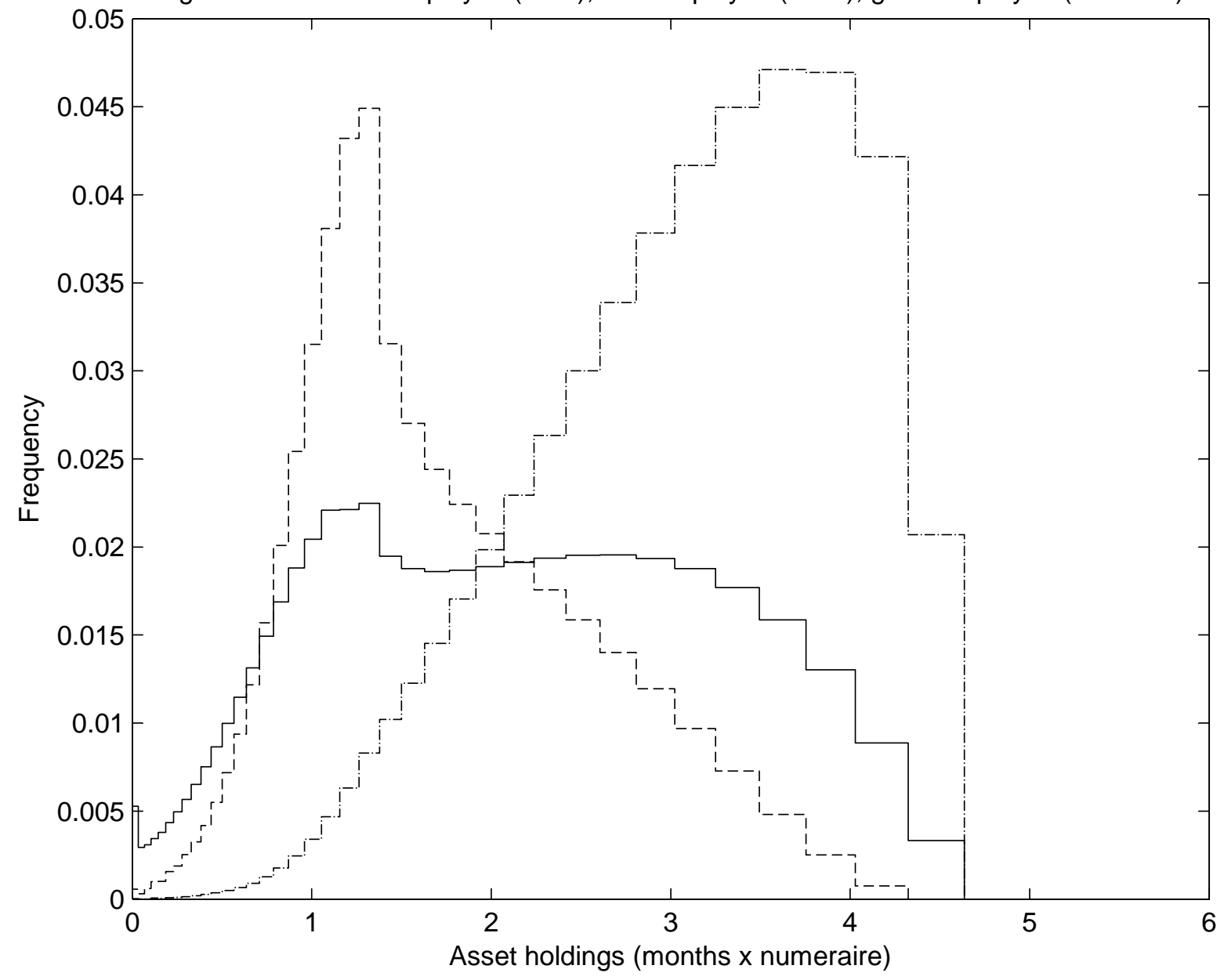


Fig. 3: Consumption policy of unemp (solid), bad emp (dash), good emp (dash dot)

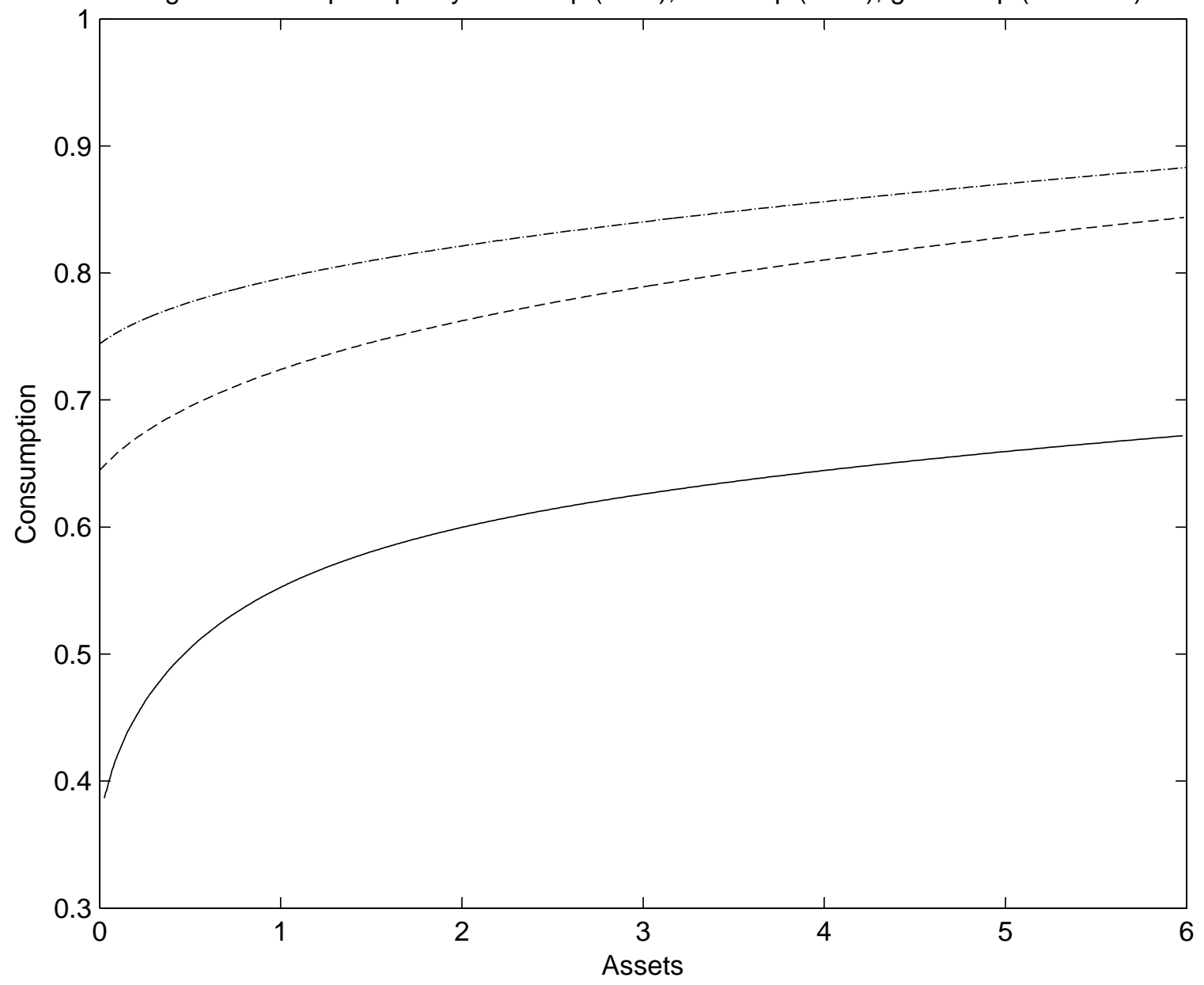


Fig. 4: Unemployment duration probabilities. Solid: boom; dashed: recession; dotted: static.

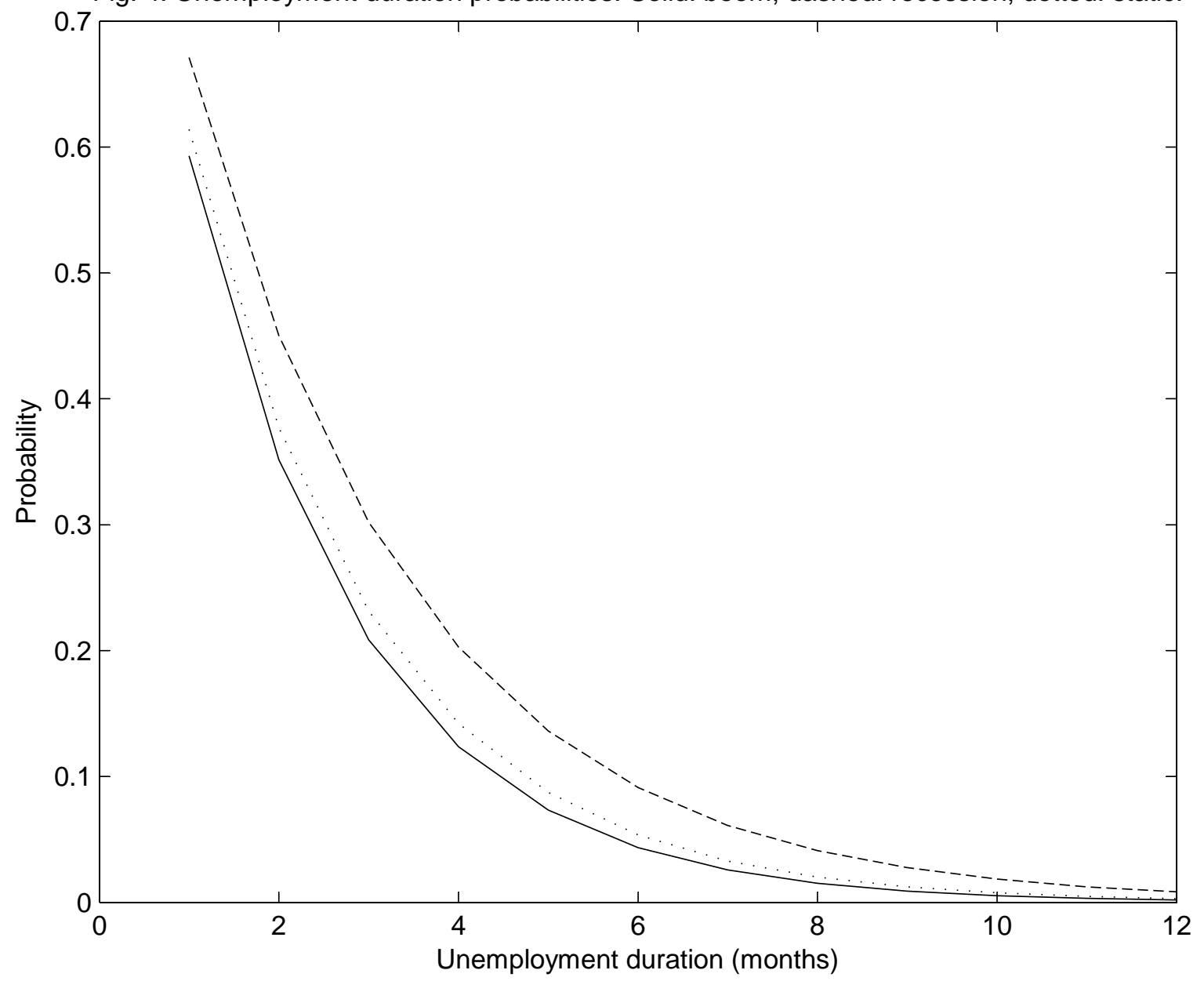


Fig. 5: Social welfare as function of policy, $b=0.32$

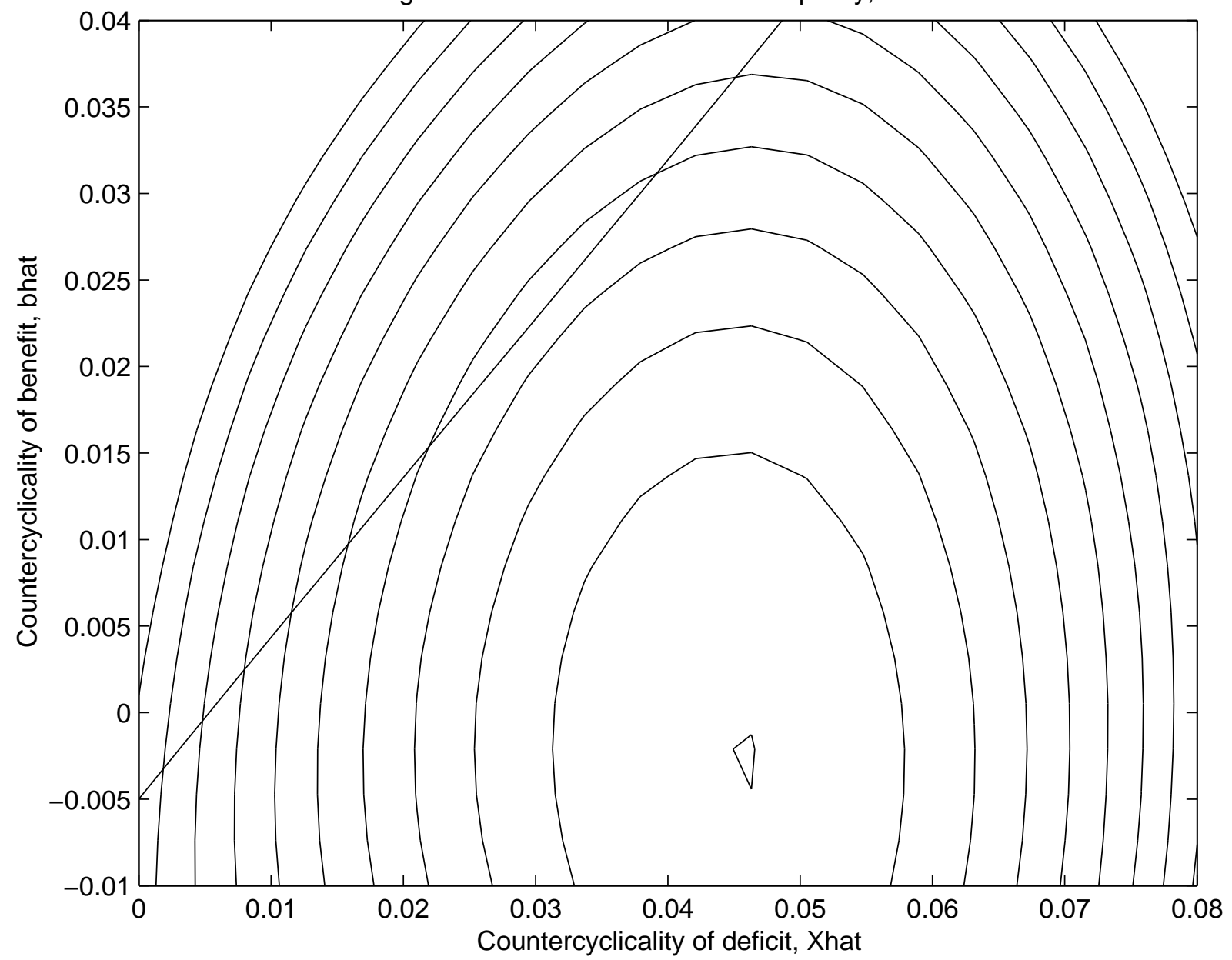


Fig. 6a: Social welfare, $b=0.30$

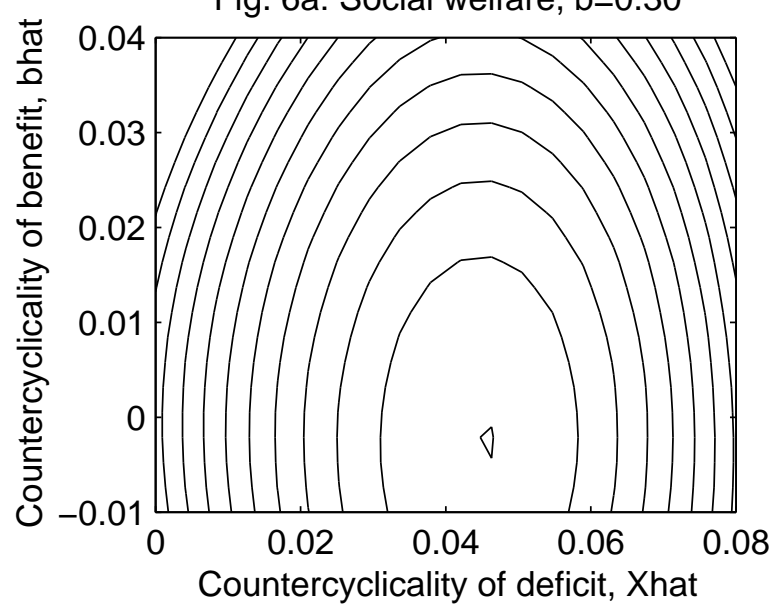

Fig. 6c: Social welfare, gamma $=3, b=0.32$

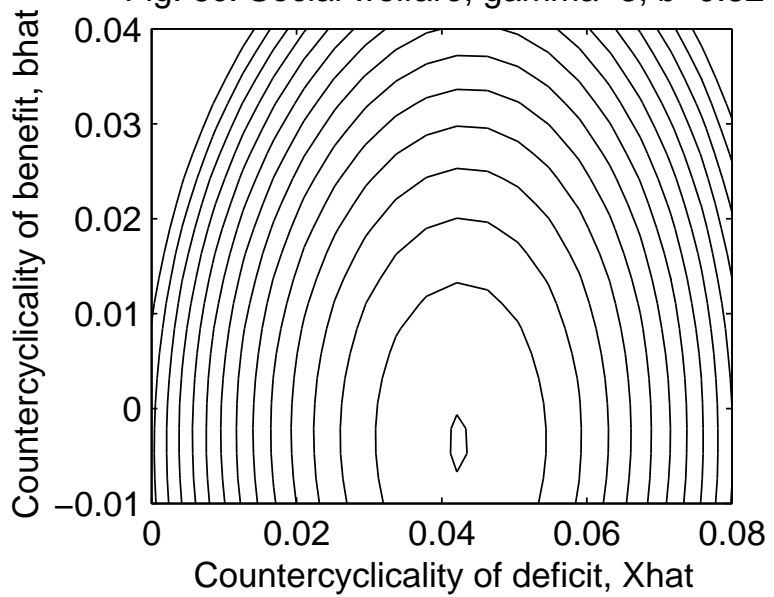

Fig. 6b: Social welfare, $b=0.34$

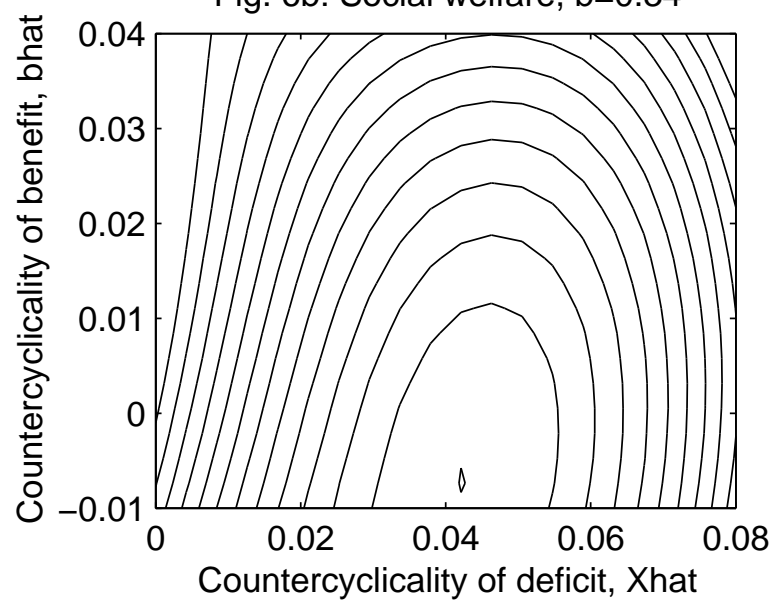

Fig. $6 \mathrm{~d}$ : Social welfare, $\mathrm{R}=1.02, \mathrm{~b}=0.32$

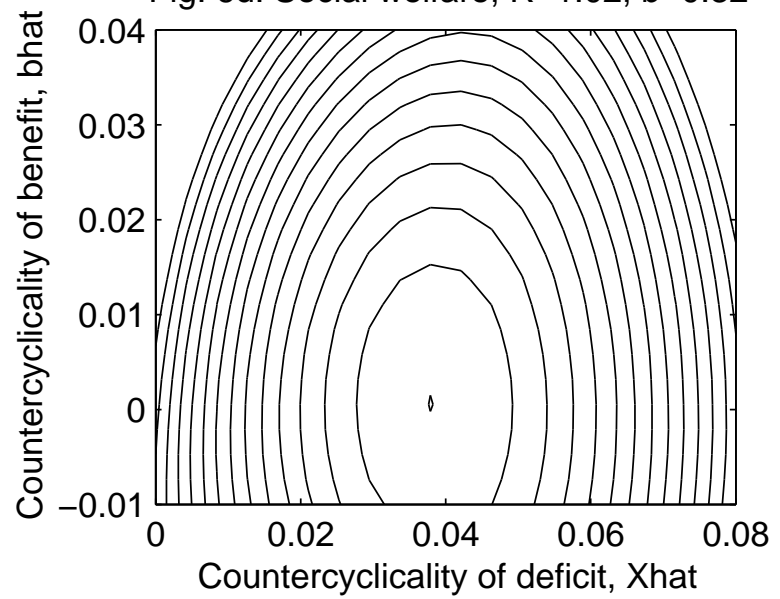

